\title{
Ensemble-based assimilation of fractional snow-covered area satellite retrievals to estimate the snow distribution at Arctic sites
}

\author{
Kristoffer Aalstad $^{1}$, Sebastian Westermann ${ }^{1}$, Thomas Vikhamar Schuler ${ }^{1}$, Julia Boike ${ }^{2}$, and Laurent Bertino ${ }^{3}$ \\ ${ }^{1}$ Department of Geosciences, University of Oslo, P.O. Box 1047, Blindern, 0316 Oslo, Norway \\ ${ }^{2}$ Alfred Wegener Institute Helmholtz Center for Polar and Marine Research, Telegrafenberg A43, 14473 Potsdam, Germany \\ ${ }^{3}$ Nansen Environmental and Remote Sensing Center, Thormøhlens gate 47, Bergen 5006, Norway
}

Correspondence: Kristoffer Aalstad (kristoffer.aalstad@geo.uio.no)

Received: 13 June 2017 - Discussion started: 4 July 2017

Revised: 1 December 2017 - Accepted: 12 December 2017 - Published: 23 January 2018

\begin{abstract}
With its high albedo, low thermal conductivity and large water storing capacity, snow strongly modulates the surface energy and water balance, which makes it a critical factor in mid- to high-latitude and mountain environments. However, estimating the snow water equivalent (SWE) is challenging in remote-sensing applications already at medium spatial resolutions of $1 \mathrm{~km}$. We present an ensemble-based data assimilation framework that estimates the peak subgrid SWE distribution (SSD) at the $1 \mathrm{~km}$ scale by assimilating fractional snow-covered area (fSCA) satellite retrievals in a simple snow model forced by downscaled reanalysis data. The basic idea is to relate the timing of the snow cover depletion (accessible from satellite products) to the peak SSD. Peak subgrid SWE is assumed to be lognormally distributed, which can be translated to a modeled time series of fSCA through the snow model. Assimilation of satellite-derived fSCA facilitates the estimation of the peak SSD, while taking into account uncertainties in both the model and the assimilated data sets. As an extension to previous studies, our method makes use of the novel (to snow data assimilation) ensemble smoother with multiple data assimilation (ES-MDA) scheme combined with analytical Gaussian anamorphosis to assimilate time series of Moderate Resolution Imaging Spectroradiometer (MODIS) and Sentinel-2 fSCA retrievals. The scheme is applied to Arctic sites near Ny-Ålesund ( $79^{\circ} \mathrm{N}$, Svalbard, Norway) where field measurements of fSCA and SWE distributions are available. The method is able to successfully recover accurate estimates of peak SSD on most of the occasions considered. Through the ES-MDA assimilation, the root-mean-square error (RMSE) for the fSCA, peak mean SWE and peak subgrid coefficient
\end{abstract}

of variation is improved by around 75, 60 and 20\%, respectively, when compared to the prior, yielding RMSEs of $0.01,0.09 \mathrm{~m}$ water equivalent (w.e.) and 0.13 , respectively. The ES-MDA either outperforms or at least nearly matches the performance of other ensemble-based batch smoother schemes with regards to various evaluation metrics. Given the modularity of the method, it could prove valuable for a range of satellite-era hydrometeorological reanalyses.

\section{Introduction}

The spatiotemporal distribution of seasonal snow cover is a key control on the terrestrial surface energy and water balance in mid- to high-latitude regions and mountainous areas (Boike et al., 2003; Barnett et al., 2005). With its high albedo and large water-holding capacity, snow is a modulator of the global radiation balance and hydrological cycle, making it one of the drivers of the atmospheric circulation and the associated climate (Andreadis and Lettenmaier, 2006; Liston, 1999). Since the snow water equivalent (SWE) can exhibit considerable variability over small distances (Clark et al., 2011), mapping the SWE distribution remains a difficult task (Dozier et al., 2016).

The primary controls on the distribution and variability of SWE are topography, vegetation, precipitation, wind, radiation and avalanching (Sturm and Wagner, 2010; Clark et al., 2011). While topography and vegetation are relatively fixed in time, the other controls vary strongly over a range of spatiotemporal scales. In unforested regions, snow tends to be affected by wind drift (e.g., Gisnås et al., 2014), leading to 
accumulation in areas with preferential deposition, such as topographic depressions or the lee side of a ridge. The scale of such features can vary dramatically across the landscape. Nonetheless, the processes occurring at a given site are often consistent from year to year, and so the SWE distribution is often quite similar to the climatological snow distribution pattern (Sturm and Wagner, 2010; Kępski et al., 2017). Manual measurement surveys are usually impractical for mapping SWE over large areas given their limited support, large spacing and small extent (Blöschl, 1999). Instead, modeling and remote sensing can be employed to map SWE.

Snow models range in complexity from relatively simple single-layer models, such as the Utah Energy Balance model (UEB; Tarboton and Luce, 1996; You et al., 2014), to detailed multilayer snowpack models, such as Crocus (Vionnet et al., 2012) and SNOWPACK (Bartelt and Lehning, 2002). Some snow models (e.g., ALPINE3D; Lehning et al., 2006) can also be run in distributed mode to simulate the snow distribution over large areas. The accuracy of the model results is limited by the hydrometeorological forcing data, be it from reanalyses or local measurements, whose errors are typically the major source of uncertainty in snow modeling (De Lannoy et al., 2010; Raleigh et al., 2015). In addition, snow models are generally developed as point-scale models; even if they are run as distributed models, the grid-scale values predicted by the model may not be representative of the corresponding process scale (Blöschl, 1999). For example, if a snow model is forced by near-point-scale hydrometeorological measurements, the model results will only be representative for a grid cell if that particular point is representative of the mean conditions within the grid cell. To circumvent this problem, probabilistic snow depletion curve (SDC) parametrizations have been developed (Liston, 1999; Luce and Tarboton, 2004; Liston, 2004) in which a probability distribution function is assigned to the SWE within a grid cell at peak accumulation. Assuming uniform melt across the grid cell, this allows for a direct relationship between the mean SWE, melt depth and fractional snow-covered area (fSCA) of the grid cell. Liston (2004) used such a SDC parametrization in conjunction with land-cover-specific subgrid coefficients of variation of SWE with the ClimRAMS model to map the fSCA over North America. As a result, the total snow-covered area increased considerably compared to the control run. Aas et al. (2017) used a tiling approach to represent subgrid snow variability in the WRF model coupled to the Noah land surface scheme over southern Norway. The tiling reduced the cold bias in the modeled near-surface air temperatures and greatly improved the match to the observed fSCA evolution. Nevertheless, due to the inherently large uncertainties in the forcing, modeling alone is usually not a sufficiently accurate tool for mapping SWE. Instead, models need to be combined with relevant data from remote sensing.

Snow-related data sets can be acquired from a variety of remote-sensing platforms with near-global coverage. The Gravity Recovery and Climate Experiment (GRACE) twin satellites allow for the retrieval of terrestrial water storage (TWS), from which SWE can be recovered at around $100 \mathrm{~km}$ spatial resolution (e.g., Niu et al., 2007). Passive microwave (PM) satellite sensors can retrieve SWE based on brightness temperature at a resolution of around $25 \mathrm{~km}$. However, PM SWE retrievals have problems over forested areas and complex topography, as well as for wet and deep snowpacks (Foster et al., 2005). Both gravimetric and PM sensors are able to retrieve SWE independent of cloud coverage, resulting in gap-free time series. While not capable of measuring SWE, moderate-resolution optical sensors such as the Moderate Resolution Imaging Spectroradiometer (MODIS) can retrieve binary information on snow cover (i.e., snow or no snow), fSCA and snow grain size (Hall et al., 2002; Salomonson and Appel, 2004; Painter et al., 2009) at approximately $500 \mathrm{~m}$ resolution with a daily revisit frequency. In addition, higher-resolution optical sensors, such as those on board the Landsat and Sentinel-2 satellites, can map fSCA at around $30 \mathrm{~m}$ resolution (e.g., Cortés et al., 2014). Optical sensors can not see through clouds, which results in data gaps over most snow-covered regions. To obtain gap-free time series, it is thus necessary to either interpolate optical remote-sensing data in time and space or ingest them in models.

Data assimilation (DA) methods can objectively fuse uncertain information from observations and models. Deterministic SWE reconstruction techniques (Girotto et al., 2014b) that directly insert remotely sensed fSCA data in models represent the simplest form of snow data assimilation. Such schemes back-calculate peak SWE from the disappearance date of the snow cover (as determined from fSCA retrievals) using snowmelt models. Martinec and Rango (1981) used Landsat fSCA retrievals during the melt season in conjunction with a simple degree day snowmelt model to estimate the peak mean SWE. Similarly, Cline et al. (1998) used Landsat fSCA retrievals combined with a distributed energy balance model to reconstruct the SWE distribution. More recently, Molotch and Margulis (2008) used fSCA information from multiple sensors for deterministic SWE reconstruction. Durand et al. (2008) introduced a probabilistic framework for SWE reconstruction. This was based on assimilating synthetic fSCA retrievals during the ablation into the Simplified Simple Biosphere version 3 (SSiB3) land surface model coupled to the SDC of Liston (2004) using the ensemble smoother (ES; Van Leeuwen and Evensen, 1996) in batch mode (cf. Dunne and Entekhabi, 2005). The assimilation of synthetic fSCA in this twin experiment was used to correct annual biases in the snowfall and facilitated the recovery of the SWE distribution. Using the Durand et al. (2008) framework, Girotto et al. (2014b) assimilated Landsat fSCA retrievals to recover the SWE distribution, yielding a significant reduction in root-mean-square error (RMSE) relative to deterministic SWE reconstruction. Subsequently, Girotto et al. (2014a) used the same framework to perform a 27-year reanalysis of SWE distributions. Recently, Margulis et al. (2015) modified this probabilistic approach by adopt- 
ing a particle batch smoother (PBS) as opposed to the ES for the assimilation of fSCA retrievals to estimate the SWE distribution. The PBS was found to outperform the ES, considerably reducing the RMSE. Based on this work, Margulis et al. (2016) adopted the PBS framework to conduct a 30year reanalysis of SWE over the Sierra Nevada (USA) using Landsat fSCA retrievals. Cortés et al. (2016) applied the same PBS framework to construct a 30-year reanalysis of SWE over six instrumented basins in the Andes. Cortés and Margulis (2017) subsequently adopted this approach to perform a 31-year SWE reanalysis over the entire extratropical Andes.

Several other snow DA techniques have recently been employed. Andreadis and Lettenmaier (2006) assimilated MODIS fSCA retrievals into the VIC model through the ensemble Kalman filter (EnKF; Evensen, 2009) using a simple SDC for the SWE-fSCA inversion. However, the improvement compared to the open loop (OL; i.e., no DA) run was only modest, which was also found in similar studies (Clark et al., 2006; Slater and Clark, 2006). A Bayesian technique was used by Kolberg and Gottschalk (2006) to assimilate Landsat fSCA retrievals into a snow model with a probabilistic SDC to estimate the peak SWE distribution. They found a significant reduction in uncertainty when retrievals were assimilated simultaneously as opposed to sequentially. At the continental scale, a multisensor assimilation of both GRACE TWS and MODIS fSCA using the ES and EnKF for TWS and fSCA, respectively, yielded significant improvements relative to the OL (Su et al., 2010). De Lannoy et al. (2010) used the EnKF in a twin experiment to assimilate synthetic PM SWE retrievals and greatly outperformed the OL. This was extended to a real multisensor experiment by jointly assimilating PM SWE and MODIS fSCA retrievals (De Lannoy et al., 2012). Li et al. (2017) used the ES to assimilate PM SWE retrievals and estimate the SWE distribution, markedly outperforming the OL. Of late, particle filter (PF; see Van Leeuwen, 2009) schemes have been gaining popularity in snow DA studies (Charrois et al., 2016; Magnusson et al., 2017). For example, Charrois et al. (2016) assimilated synthetic optical reflectance retrievals into Crocus using the sequential importance re-sampling $\mathrm{PF}$ at a point scale and considerably outperformed the OL.

It is worth emphasizing that the most popular schemes in the snow DA community, both the EnKF and the PF, are filters (i.e., sequential techniques). As such, they are Markovian of order 1 (memoryless): the future state at a given point in time depends only on the present state. Furthermore, observations are assimilated sequentially with only the current observation affecting the current state. Batch smoothers (Dunne and Entekhabi, 2005), on the other hand, take into account the entire history of a model trajectory within a batch (observation window) and as such have memory (non-Markovian) so that they are better suited for reanalysis problems.

In this study, we build on the probabilistic SWE reconstruction technique outlined in Girotto et al. (2014b) to re- cover subgrid SWE distributions (SSDs) for a study area in the Arctic based on FSCA retrievals from MODIS and Sentinel-2. The novelty of our study lies in the use of an iterative batch smoother scheme, namely the ensemble smoother with multiple data assimilation (ES-MDA; Emerick and Reynolds, 2013). To update physically bounded parameters, we make use of analytical Gaussian anamorphosis (Bertino et al., 2003). We investigate the performance of the ES-MDA in terms of SWE reconstruction and compare it to the ES and the PBS employed by Girotto et al. (2014b) and Margulis et al. (2015), respectively. The results are evaluated against independent field measurements of fSCA and snow surveys conducted over six snow seasons.

\section{Study area}

\subsection{Physical characteristics and climate}

The study area is located in NW Svalbard close to the research town of $\mathrm{Ny}$-Ålesund $\left(78^{\circ} 55^{\prime} \mathrm{N}, 11^{\circ} 50^{\prime} \mathrm{E}\right)$ on the Brøgger Peninsula. Field measurements are available from three sites (Fig. 1). "Bayelva", about $2 \mathrm{~km}$ west of $\mathrm{Ny}$ Alesund, is the main study site where multiyear in situ records on, for instance, the surface energy balance, permafrost thermal regime and snow distribution are available (Westermann et al., 2009; Gisnås et al., 2014; Boike et al., 2017). In addition, snow surveys for a single season (2016) are available from "Steinflåen plateau" and "Kvadehuksletta". All sites feature gently undulating topography with small hills and surfaces characterized by patterned ground features, leading to strong differences in snow cover due to wind drift. Bayelva and Kvadehuksletta are located between 10 and $50 \mathrm{ma}$ a.s.l., while the Steinflåen plateau is at a higher elevation of around $200 \mathrm{~m}$ a.s.l. Kvadehuksletta is exposed to most wind directions, whereas Bayelva and Steinflåen plateau are partly sheltered by mountains. The sites are located within the continuous permafrost zone (Boike et al., 2003 ) with a maximum active layer depth of around $1.5 \mathrm{~m}$ at the Bayelva site (Westermann et al., 2009).

The Bayelva site is located around the heavily instrumented Bayelva climate and soil monitoring station (Boike et al., 2017). This area has been the subject of extensive studies spanning permafrost (Roth and Boike, 2001; Boike et al., 2008; Westermann et al., 2011a), the surface energy balance (Boike et al., 2003; Westermann et al., 2009), $\mathrm{CO}_{2}$ exchange (Lüers et al., 2014; Cannone et al., 2016), ecology (Kohler and Aanes, 2004), snow (Bruland et al., 2001; Gisnås et al., 2014; López-Moreno et al., 2016), hydrology (Nowak and Hodson, 2013) and satellite retrieval validation (Westermann et al., 2011b, 2012). The surface cover at Bayelva and Kvadehuksletta alternates between bare soil, rocks and sparse low vegetation (Westermann et al., 2009), while the more elevated Steinflån plateau is predominantly covered by loose rocks. 


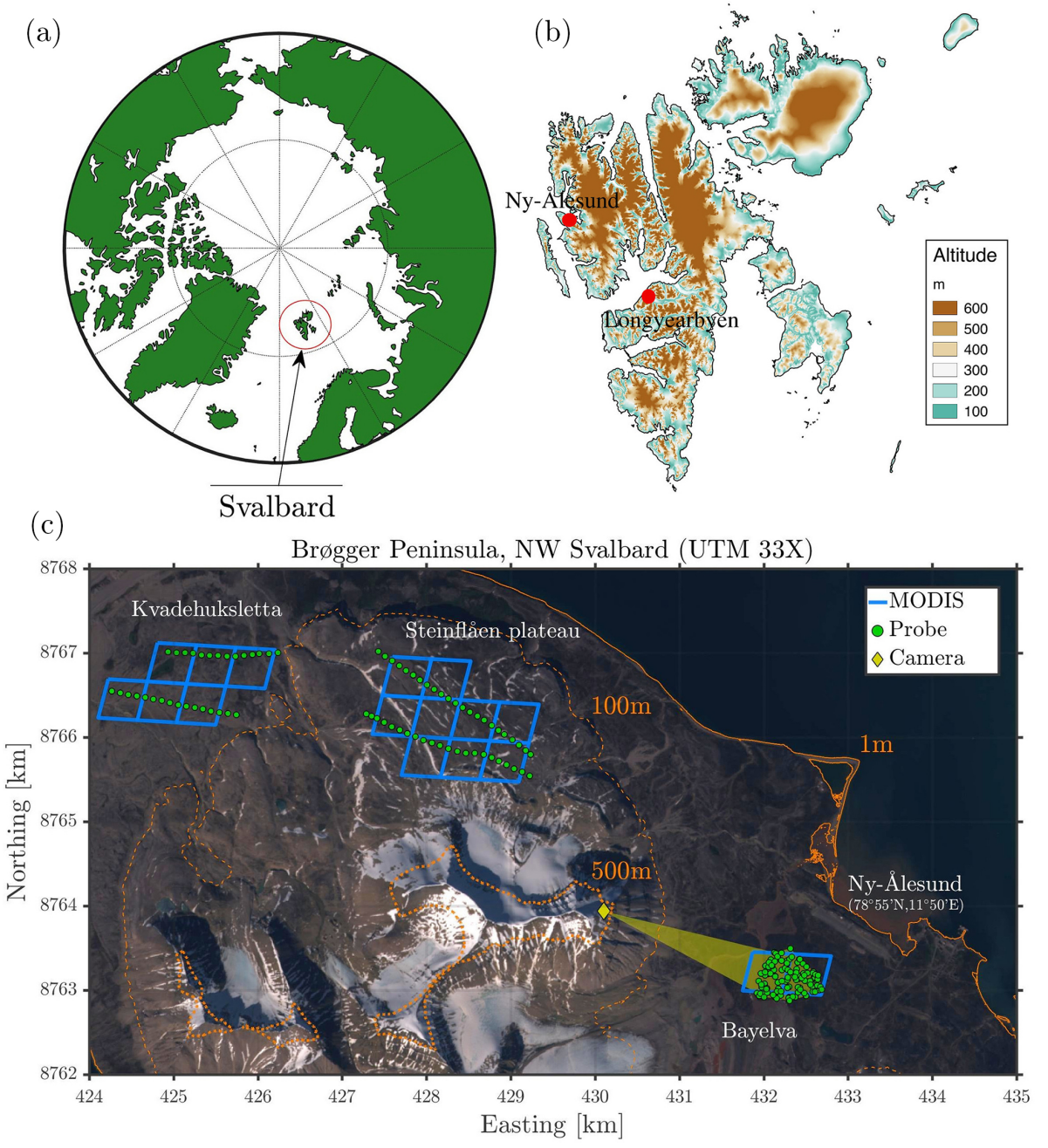

Figure 1. (a) location of Svalbard (in red) in the Arctic. (b) Map of Svalbard; the study area is close to Ny-Ålesund. Bottom: Sentinel-2A true-color image (2 July 2016) of the western Brøgger Peninsula with the three study sites Kvadehuksletta, Steinflåen plateau and Bayelva; green dots: snow survey probe locations; blue polygons: MODIS pixels; yellow diamond: automatic camera system on Scheteligfjellet; yellow shading: field of view of the camera; contour lines courtesy of the NPI (2014) DEM.

The climate of western Svalbard is influenced by the relatively warm West Spitsbergen Current causing a maritime climate with mild winters and cool summers for this latitude (Esau et al., 2012). At Ny-Ålesund the winter, summer and annual (1981-2010) average air temperatures were -12.0 , 3.8 and $-5.2^{\circ} \mathrm{C}$, respectively, while the average annual precipitation was $427 \mathrm{~mm}$ (Førland et al., 2011). Between September/October and May the precipitation mainly falls as snow, although rain-on-snow events have become more frequent due to the warming of the local climate (Nowak and Hodson, 2013; López-Moreno et al., 2016). The seasonal snow cover usually forms in late September or early October and lasts until mid-June to early July, with a melt season of around 1 month (Winther et al., 2002). The dominant energy source during the snowmelt is radiation (longwave and shortwave), while the heat flux required to warm the frozen ground underlying the snow is an important energy sink (Boike et al., 2003; Westermann et al., 2009).

\subsection{Field measurements}

Manual surveys of snow depth and density were carried out in April/May for 6 years at the Bayelva site and for 1 year (2016) at the two other sites (Table 1). At this time, the snow depth is near its maximum but the snowpack is still dry. The snow density was sampled in vertical layers at every fifth point. As no systematic stratification of the snow density was found, SWE was finally calculated from snow depth and the average snow density at each site in a given year. At Bayelva, the snow density was generally confined to a range of $350 \pm 50 \mathrm{~kg} \mathrm{~m}^{-3}$ for all the surveys, while the snow density was found to be around $450 \mathrm{~kg} \mathrm{~m}^{-3}$ at Steinflåen plateau in 2016. At Kvadehuksletta and Steinflåen plateau, the sur- 
Table 1. Overview of the study sites and snow surveys. $\bar{z}$ is the mean elevation, and $\sigma_{z}$ is the standard deviation in the elevation, both based on the NPI (2014) DEM. t: transect; ${ }^{\mathrm{r}}$; randomized array.

\begin{tabular}{llllll}
\hline Location & $\bar{z}[\mathrm{~m}$ a.s.1.] & $\sigma_{z}[\mathrm{~m}]$ & Area $\left[\mathrm{km}^{2}\right]$ & Survey years & Samples per survey \\
\hline Bayelva & 23 & 9 & 0.5 & $2008,2009,2013-2016$ & $853^{\mathrm{t}}, 617^{\mathrm{t}}, 105^{\mathrm{r}}$ \\
Steinflåen plateau & 210 & 11 & 1.1 & 2016 & $45^{\mathrm{t}}$ \\
Kvadehuksletta & 55 & 6 & 0.9 & 2016 & $30^{\mathrm{t}}$ \\
\hline
\end{tabular}

veys were conducted along transects with regular sample intervals (see Fig. 1). A randomized array of sample points was employed for Bayelva in most years, except for the first 2 years where transects were used.

Basal ice layers resulting from rain-on-snow events (Kohler and Aanes, 2004; Westermann et al., 2011a) occur in the area and can constitute a major source of uncertainty for SWE measurements. In 2016, the depth of basal ice layers was measured using ice screws, and their contribution to the SWE was accounted for. In addition, internal ice layers and the spatial variability of average snow densities (see above) contribute to the uncertainty of the measurements. Furthermore, only a limited number of sampling points are available, so that the obtained snow distributions are expected to deviate to a certain extent from the true snow distributions in the area. Although the snow surveys coincide closely with peak SWE, some accumulation (ablation) may occur after (before) the surveys. To assess the magnitude of this error source, we used snow depth measurements at the Bayelva station (Boike et al., 2017) to compare the snow depth at the survey dates to the maximum snow depth for each snow season. We found an average relative difference of $8 \%$ (maximum: $17 \%$; minimum: $0.3 \%$ ).

In 2012, 2013 and 2016, an automatic time-lapse camera was deployed near the summit of Scheteligfjellet (694 ma.s.l.; cf. Fig. 1), overlooking the Bayelva site. The camera was a standard digital camera triggered by a Harbortronics time-lapse system, delivering daily images except for prolonged periods with low cloud cover. The raw camera images were orthorectified at a $1 \mathrm{~m}$ resolution, and snow was mapped for each pixel using a threshold on the intensity, so that fSCA could be determined for each image. The orthorectified images for two of the years are freely available in Westermann et al. (2015a).

In 2008, aerial images were obtained for the Bayelva site for five dates in June during the beginning of the snowmelt period. This was accomplished by mounting a digital camera to an unmanned aerial vehicle (UAV) flying at an altitude of 100 to $250 \mathrm{~m}$ above ground which took between 700 and 1000 images per mission at nadir angles. As the images were taken in a near-random fashion over the entire area, fSCA was calculated by averaging over the fSCA determined for each image using a simple threshold criterion. GPS-based surveys of the remaining snow patches were available for five additional dates, so that a complete fSCA time series is available for the snowmelt period in 2008 .

\section{Method}

\subsection{Simple snow model}

To efficiently run a large number of ensemble members, a simple snow model (SSM) is employed, which computes snowmelt rates according to surface energy balance formulations (as in the CryoGrid 3 ground thermal model; Westermann et al., 2016). The model is a blend of a single-layer mass balance scheme, based on the UEB model (Tarboton and Luce, 1996; You et al., 2014), and the Liston (2004) SDC. Many internal snow processes (occurring inside the snowpack), including heat conduction and meltwater percolation, are omitted. In addition, several external processes such as sublimation and deposition are ignored. In the following sections, we describe the governing equations of the SSM (see Table 2 for the model constants).

\subsubsection{Snow depletion curve}

We use the SDC parametrizations discussed in Liston (1999), Luce and Tarboton (2004) and Liston (2004) which parametrize the relationship between ISCA, melt depth and SWE by using a probability density function (pdf) to represent the peak SSD. A key assumption is that the melt rate is spatially uniform within each grid cell. The relationship between the accumulated melt depth $\left(D_{\mathrm{m}}\right)$, the peak SSD pdf $\left(f_{\mathrm{P}}\right)$ and the $\mathrm{fSCA}$ within the grid cell at time $t$ is given by

$\operatorname{fSCA}(t)=\int_{D_{\mathrm{m}}(t)}^{\infty} f_{\mathrm{P}}(D) \mathrm{d} D$.

Similarly, the mean SWE depth is given by

$\bar{D}(t)=\int_{D_{\mathrm{m}}(t)}^{\infty}\left(D-D_{\mathrm{m}}(t)\right) f_{\mathrm{P}}(D) \mathrm{d} D$.

Following Liston (2004), we parametrize the peak SSD using a two-parameter lognormal pdf $f_{\mathrm{P}}=f_{\mathrm{P}}(D \mid \mu, \chi)$, where $\mu$ is the peak mean SWE and $\chi=\sigma / \mu$ is the peak subgrid coefficient of variation ( $\sigma$ is the standard deviation). $\chi$ is a 
Table 2. List of the model constants used in the simple snow model runs along with the corresponding reference studies.

\begin{tabular}{lllll}
\hline Symbol & Name & Value & Units (SI) & Reference \\
\hline$\alpha_{\mathrm{max}}$ & Maximum snow albedo & 0.85 & - & Dutra et al. (2010) \\
$\tau_{\mathrm{S}}$ & Threshold snowfall & 0.01 & $\mathrm{~m}$ (w.e.) & Dutra et al. (2010) \\
$\tau_{\mathrm{F}}$ & Aging constant for melting snow & $2.78 \times 10^{-8}$ & $\mathrm{~s}^{-1}$ & Dutra et al. (2010) \\
$\tau_{\mathrm{A}}$ & Aging constant for non-melting snow & $9.26 \times 10^{-8}$ & $\mathrm{~s}$ & Dutra et al. (2010) \\
$T_{\mathrm{R}}$ & Threshold temperature for rain & 276.15 & $\mathrm{~K}$ & You et al. (2014) \\
$T_{\mathrm{S}}$ & Threshold temperature for snow & 272.15 & $\mathrm{~K}$ & You et al. (2014) \\
$\varepsilon_{\mathrm{S}}$ & Emissivity of snow & 0.99 & - & Westermann et al. (2016) \\
$d_{\mathrm{H}}$ & Thermal diffusivity of the ground & $6 \times 10^{-7}$ & $\mathrm{~m}^{2} \mathrm{~s}^{-1}$ & Westermann et al. (2009) \\
$z_{\mathrm{E}}$ & Effective transfer depth & 1 & $\mathrm{~m}^{-1}$ & - \\
$\Delta t$ & Daily time step & 86400 & $\mathrm{~s}$ & - \\
$L_{\mathrm{f}}$ & Specific latent heat of fusion & $3.35 \times 10^{5}$ & $\mathrm{~J} \mathrm{~kg}^{-1}$ & Tarboton and Luce (1996) \\
$\rho_{\mathrm{W}}$ & Density of fresh liquid water & $10^{3}$ & $\mathrm{~kg} \mathrm{~m}^{-3}$ & Tarboton and Luce (1996) \\
$\sigma_{\mathrm{SB}}$ & Stefan-Boltzmann constant & $5.67 \times 10^{-8}$ & $\mathrm{~W} \mathrm{~m}^{-2} \mathrm{~K}^{-4}$ & Tarboton and Luce (1996) \\
\hline
\end{tabular}

perturbation parameter (see Table 4) that is updated in the assimilation. Our choice of parametric distribution was motivated by independent measurements of the SSD which fit reasonably well to a lognormal distribution (Bruland et al., 2001). Equations (1) and (2) can both be solved analytically as presented in Liston (2004).

\subsubsection{Mass and energy balance}

To obtain the instantaneous net accumulation rate, $\mathcal{A}(t)$, we follow the UEB model through (You et al., 2014)

$\mathcal{A}(t)=P(t)-M(t)$,

where $P(t)$ is the precipitation rate and $M(t)$ is the melt rate. Sublimation is not considered as it is a relatively small contribution to the mass balance at our study area (Westermann et al., 2009). We use a linear transition to delineate between snowfall and rainfall (You et al., 2014), with thresholds given in Table 2. We only consider rainfall as a positive contribution to the mass balance during non-melting conditions when the rainwater generally refreezes in the snowpack (Westermann et al., 2011a). For melting conditions (where $D_{\mathrm{m}}>0$ ), we assume that rainfall directly becomes runoff.

The melt rate, $M$, is calculated based on a simplified snow energy balance defined by

$Q_{\mathrm{M}}(t)=Q_{\mathrm{R}}^{*}(t)+Q_{\mathrm{P}}(t)-Q_{\mathrm{H}}(t)-Q_{\mathrm{E}}(t)-Q_{\mathrm{G}}(t)$,

where $Q_{\mathrm{M}}$ is the snowmelt flux, $Q_{\mathrm{R}}^{*}$ is the global radiation, $Q_{\mathrm{P}}$ is the heat advected by precipitation, $Q_{\mathrm{H}}$ is the sensible heat flux, $Q_{\mathrm{E}}$ is the latent heat flux and $Q_{\mathrm{G}}$ is the ground heat flux. The last three fluxes are defined as positive when directed away from the surface and vice versa for the first two on the right-hand side of Eq. (4). The SSM differs from UEB in that we calculate the surface energy balance for a melting snowpack, i.e., isothermal at $0{ }^{\circ} \mathrm{C}$, at all times. In this case, the global radiation is

$Q_{\mathrm{R}}^{*}=\left(1-\alpha_{\mathrm{S}}\right) S^{\downarrow}+L^{\downarrow}-\varepsilon_{\mathrm{S}} \sigma_{\mathrm{SB}} T_{0}^{4}$, in which $S^{\downarrow}$ and $L^{\downarrow}$ are the downwelling shortwave and longwave irradiances, and the last term is the upwelling longwave radiation for the assumed isothermal snowpack at $T_{0}=$ $273.15 \mathrm{~K}$. The snow albedo $\left(\alpha_{\mathrm{S}}\right)$ is parametrized prognostically through the continuous reset formulation following Dutra et al. (2010), which computes the albedo for time increments $\Delta t$ by distinguishing between accumulating, steady and ablating conditions:

$\alpha_{\mathrm{S}}(t+\Delta t)=$

$\begin{cases}\alpha_{\mathrm{S}}(t)+\min \left(1, \mathcal{A}(t) \Delta t / \tau_{\mathrm{S}}\right)\left(\alpha_{\max }-\alpha_{\mathrm{S}}(t)\right), & \mathcal{A}(t)>0, \\ \max \left(\alpha_{\mathrm{S}}(t)-\tau_{\mathrm{A}} \Delta t, \alpha_{\min }\right), & \mathcal{A}(t)=0, \\ \left(\alpha_{\mathrm{S}}(t)-\alpha_{\min }\right) \exp \left(-\tau_{\mathrm{F}} \Delta t\right)+\alpha_{\min }, & \mathcal{A}(t)<0 .\end{cases}$

Here, $\alpha_{\min }$ and $\alpha_{\max }$ are the minimum and maximum snow albedo values, respectively, while $\tau_{\mathrm{A}}$ and $\tau_{\mathrm{F}}$ are aging (decay) rates for non-melting and melting snow, respectively. $\tau_{\mathrm{S}}$ is a threshold for daily snowfall which, if exceeded, leads to a reset of the snow albedo to its maximum value. $\alpha_{\min }$ is a perturbation parameter (see Table 4) that is updated in the assimilation. This simple decay and reset type of snow albedo parametrization has been shown to perform reasonably well at Bayelva (Pedersen and Winther, 2005). The heat advected by rainfall $\left(Q_{\mathrm{P}}\right)$ is computed as in Tarboton and Luce (1996), while the turbulent fluxes of sensible $\left(Q_{\mathrm{H}}\right)$ and latent $\left(Q_{\mathrm{E}}\right)$ heat are evaluated following Westermann et al. (2016). The ground heat flux $\left(Q_{\mathrm{G}}\right)$ is parametrized through a simple efolding relationship during the melting period, i.e.,

$Q_{\mathrm{G}}=Q_{0} \exp \left(-d_{\mathrm{H}} t_{\mathrm{m}} / z_{\mathrm{E}}^{2}\right)$

where $Q_{0}$ is the initial ground heat flux, $d_{\mathrm{H}}$ is the thermal diffusivity of the ground, $z_{\mathrm{E}}$ is the effective depth of the heat transfer below the base of the snowpack and $t_{\mathrm{m}}$ is the number of days with melting conditions after peak accumulation. $Q_{0}$ is a perturbation parameter (see Table 4) that is updated in the 
assimilation, $d_{\mathrm{H}}$ is selected according to field measurements (Westermann et al., 2009) and $z_{\mathrm{E}}$ is set so that the ground heat flux decays to near zero a month into the melt season.

The snowmelt flux $Q_{\mathrm{M}}$ can now be evaluated through Eq. (4). We recall that an isothermal snowpack at $0{ }^{\circ} \mathrm{C}$ is assumed for Eq. (4), which is only justified for a melting snowpack. In this case, positive $Q_{\mathrm{M}}$ values correspond to melting and SWE reduction, while negative values correspond to refreezing of meltwater and thus SWE increase. For a dry snowpack (as is generally the case before the snowmelt), negative $Q_{\mathrm{M}}$ values would lead to a cooling of the snowpack, which is not considered in this simple snowmelt scheme. To discard unphysical values (negative melt rates), we only consider days with net melting conditions, i.e., positive daily average snowmelt fluxes. Thus, the daily averaged melt rate $M_{n}$ at day $n$ (lasting from $t_{n}$ to $t_{n+1}$ ) is given by

$M_{n}=\max \left(\frac{1}{\rho_{\mathrm{w}} L_{\mathrm{f}} \Delta t} \int_{t_{n}}^{t_{n+1}} Q_{\mathrm{M}}(t) \mathrm{d} t, 0\right)$,

where $\rho_{\mathrm{W}}$ is the density of freshwater, $L_{\mathrm{f}}$ is the latent heat of fusion and $\Delta t$ is the daily time step. We emphasize that the effects of refreezing are still considered at a subdaily time resolution in Eq. (8). Similarly, the daily averaged precipitation rate is

$P_{n}=\frac{1}{\Delta t} \int_{t_{n}}^{t_{n+1}} P(t) \mathrm{d} t$.

Now the daily averaged net accumulation rate can be obtained through

$\mathcal{A}_{n}=P_{n}-M_{n}$,

and the accumulated melt depth $D_{\mathrm{m}}$ is accounted for through

$D_{m, n+1}=\max \left(D_{m, n}-\mathcal{A}_{n} \Delta t, 0\right) H(\mu)$.

The peak mean SWE $\mu$ is updated via

$\Lambda=\mu_{n}+\max \left(\mathcal{A}_{n} \Delta t-D_{m, n+1}, 0\right)$

through

$\mu_{n+1}=\Lambda H\left(\Lambda-\tau_{\mathrm{S}}\right)$,

where the alternative Heaviside function is defined through $H(x)=0$ if $x \leq 0$ and $H(x)=1$ otherwise. Consequently, in Eq. (13) the peak mean SWE $\mu$ is only nonzero if $\Lambda$ exceeds the threshold $\tau_{\mathrm{S}}$. Note that the formulation in Eq. (11) gradually resets the melt depth towards zero in the case of snowfall after the onset of melt, following Liston (2004). This means that fSCA is not reset to unity in the case of new snowfall after a melting period unless the new snowfall leads to an increase in the peak SWE. In the study area, snowfall events occurred rarely during the snowmelt period, and the new snow cover lasted only a short time. At sites where such events are more frequent, Durand et al. (2008) presents an alternative solution, albeit at an increased computational cost. The annual model integrations start in the beginning of September, when the surface is assumed to be snow free, so that both $\mu$ and $D_{\mathrm{m}}$ are initialized as zero. Both $\mu$ and $D_{\mathrm{m}}$ are reset to zero following the complete disappearance of the snowpack, defined as when the ISCA decreases below 0.01 to account for the infinite tail of $f_{\mathrm{P}}$. The model resolution is defined by the footprint of (area encompassed by) the snow surveys for each site (see Table 1 and Fig. 1).

\subsubsection{Forcing}

Forcing terms in the form of precipitation, air temperature, relative humidity and wind speed, as well as downwelling longwave and shortwave radiation, are required to diagnose the mass and energy balance in Eq. (3) and Eq. (4). These terms are obtained by downscaling ERA-Interim reanalysis data (Dee et al., 2011) at $0.75^{\circ}$ resolution following Østby et al. (2017). This method uses the linear theory of orographic precipitation in Smith and Barstad (2004) to downscale precipitation and a modification of the TopoSCALE approach (Fiddes and Gruber, 2014) for the remaining fields. The reanalysis forcing is downscaled onto $1 \mathrm{~km}$ resolution digital elevation model (DEM) grid cells centered on each of the study sites. The downscaling is performed based on the mean physiographic conditions (elevation, slope and aspect) within each of these grid cells. The resulting values at $1 \mathrm{~km}$ spatial and 6-hourly temporal resolution are linearly interpolated in time to facilitate a stable computation of the time evolution of turbulent energy fluxes following Westermann et al. (2016). From these fluxes, and the remaining surface energy balance fields, diurnally averaged melt rates are calculated. Similarly, diurnally averaged rainfall and snowfall rates are computed by delineating between rain and snow in the time-interpolated precipitation rate (You et al., 2014) and then taking diurnal averages. While the resolution of the downscaled forcing data does not exactly match the model resolution (i.e., the footprint of the snow surveys, Sect. 3.1.2), the mismatch is small considering the gentle topography of the study sites (Sect. 2.1).

\subsection{Satellite retrievals}

We make use of satellite retrievals between May and September, which contain the snowmelt period for all the investigated years. Only retrievals that fall inside the melt season are assimilated as these contain information about the snow cover depletion. Due to frequent cloud cover, the effective revisit frequency of fSCA retrievals is irregular, with prolonged data gaps occurring regularly. An overview of the number of available scenes is given in Table 3 . 
Table 3. Number of MODIS and Sentinel-2 scenes per melt season with field measurements available for the three study sites.

\begin{tabular}{llll}
\hline Location & Melt season & No. of MODIS scenes & No. of Sentinel-2 scenes \\
\hline Bayelva & $2008,2009,2012,2013,2014,2015,2016$ & $8,9,8,9,6,14,11$ &,,,,,,------ 7 \\
Steinflåen plateau & 2016 & 5 & 8 \\
Kvadehuksletta & 2016 & 11 & 7 \\
\hline
\end{tabular}

Table 4. Overview of the distributions from which the prior ensemble of perturbation parameters are independently drawn.

\begin{tabular}{lllllll}
\hline Symbol & Name & Distribution & Support & Mean & Variance & Units \\
\hline$\chi$ & Coefficient of variation & Logit-normal & $(0,0.8)$ & 0.4 & 0.01 & - \\
$Q_{0}$ & Initial ground heat flux & Logit-normal & $(0,40)$ & 20 & 20 & $\mathrm{~W} \mathrm{~m}^{-2}$ \\
$\alpha_{\min }$ & Minimum snow albedo & Logit-normal & $(0.45,0.55)$ & 0.5 & 0.02 & - \\
$b_{\mathrm{P}}$ & Precipitation bias & Lognormal & $(0, \infty)$ & 1 & 0.04 & - \\
$b_{\mathrm{M}}$ & Melt bias & Lognormal & $(0, \infty)$ & 1 & 0.01 & - \\
\hline
\end{tabular}

\subsubsection{MODIS}

We employ version 6 of the Level 3 daily $500 \mathrm{~m}$ resolution fSCA retrievals from MODIS on board the satellites Terra (MOD10A1 product; Hall and Riggs, 2016a) and Aqua (MYD10A1 product; Hall and Riggs, 2016b). The retrieval algorithm is based on a linear fit of the normalized difference snow index (NDSI) measured by MODIS to fSCA retrievals from ground truth Landsat scenes as described in Salomonson and Appel (2004). The NDSI exploits the fact that snow is highly reflective in the visible but a good absorber in the shortwave infrared, which sets it apart from other natural surfaces such as clouds, vegetation and soil (Painter et al., 2009).

We average over all the pixels for each day and study site (see Fig. 1). This average is only taken if cloud-free (as determined by the MODIS cloud mask) retrievals are available for each of these pixels. If both Terra and Aqua retrievals are available for a given day, only the former are used. Despite small deviations in the measurement footprint (see Fig. 1), we compare MODIS fSCA retrievals to the field measurements of fSCA obtained from the automatic camera system, UAV and GPS surveys (Sect. 2.2). From this comparison, we estimate a RMSE of $\sigma_{\mathrm{MOD}}=0.13$ for the MODIS fSCA. We use $\sigma_{\mathrm{MOD}}^{2}$ as the observation error variance in the corresponding diagonal entries of the observation error covariance matrix (Sect. 3.3.2).

\subsubsection{Sentinel-2}

For the year 2016, we complement the MODIS fSCA retrievals with aggregated $20 \mathrm{~m}$ resolution retrievals from the Sentinel-2A mission (Drusch et al., 2012). fSCA estimates are derived from the Level $1 \mathrm{C}$ orthorectified top of the atmosphere reflectance product, with cloud-free scenes manually selected. For this purpose, NDSI is computed from reflectances $(r)$ from a visible (b3, centered on $0.56 \mu \mathrm{m}$ ) and a shortwave infrared band (b11, centered on $1.61 \mu \mathrm{m})$ through
$\operatorname{NDSI}_{\mathrm{S} 2}=\frac{r_{\mathrm{b} 3}-r_{\mathrm{b} 11}}{r_{\mathrm{b} 3}+r_{\mathrm{b} 11}}$.

Each pixel is then classified as either snow covered (NDSI $\geq$ $0.4)$ or snow free (NDSI $<0.4$ ), where the NDSI threshold was chosen in line with Hall et al. (2002). The binary (snow/no snow) pixels are then aggregated to the approximate footprint of the independent snow surveys conducted at each site (Fig. 1) to obtain Sentinel-2-derived fSCA estimates. Therefore, the areal extent of the Sentinel-2 fSCA retrievals closely matches the areas of the corresponding study sites given in Table 1. The retrieval process is illustrated schematically in Fig. 2. By comparing the Sentinel-2 retrievals to the field measurements of fSCA from the automatic camera system in 2016, we estimate a RMSE of $\sigma_{\mathrm{S} 2}=0.09$. We use $\sigma_{\mathrm{S} 2}^{2}$ as the observation error variance in the corresponding diagonal entries of the observation error covariance matrix (Sect. 3.3.2).

\subsection{Ensemble data assimilation}

In this section we outline how the prior ensemble of model realizations is set up and how it is updated to a posterior ensemble through the assimilation of fSCA satellite retrievals using ensemble-based batch smoother schemes.

\subsubsection{Ensemble generation}

The prior ensemble of model realizations is generated by independently drawing perturbation parameter values from the distributions listed in Table 4. These perturbation parameters are held constant throughout the annual integration of the model. Two of these are multiplicative bias parameters that perturb the mass balance through the net accumulation rate,

$$
\mathcal{A}_{n, j}=b_{P, j} P_{n}-b_{M, j} M_{n, j},
$$



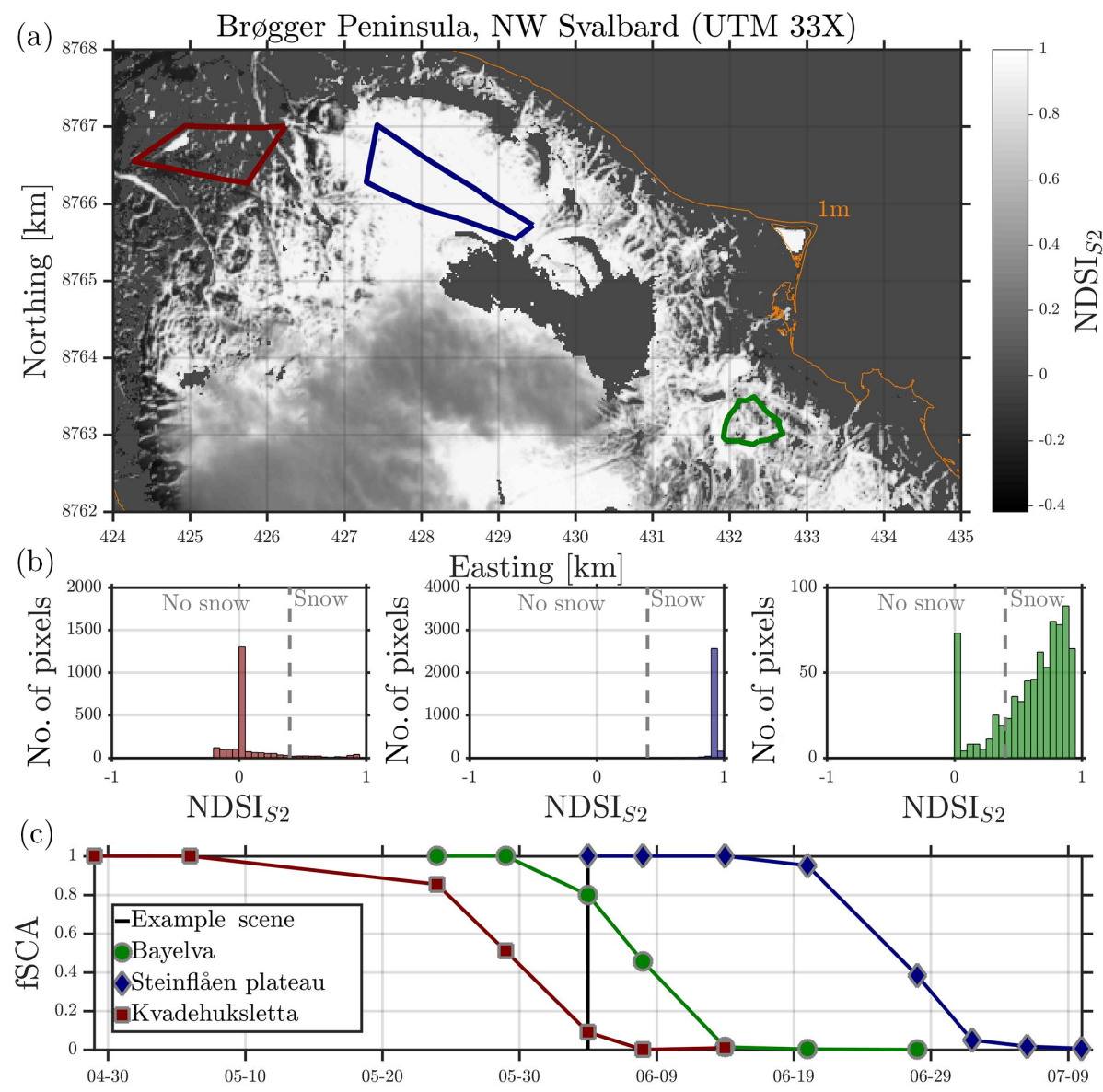

Figure 2. (a) Sentinel-2 NDSI estimates from an example scene (4 June 2016) over the Brøgger Peninsula with Kvadehuksletta, Steinflåen plateau and Bayelva marked with red, green and blue polygons, respectively; coastline in orange. (b) NDSI histograms of the same example scene (Kvadehuksletta: left; Steinflåen plateau: middle; Bayelva: right) with the threshold at NDSI=0.4 marked. (c) Time series of Sentinel-2 NDSI-based fSCA retrievals for the 2016 melt season.

for $j \in 1: N_{\mathrm{e}}$, where $N_{\mathrm{e}}$ is the number of ensemble members. We inherently assume the model forcing to be the major source of uncertainty (De Lannoy et al., 2010; Raleigh et al., 2015). Furthermore, we assume that the error in the forcing can be modeled through constant multiplicative biases (fixed throughout the annual integration) in the mass balance. Consequently, the bias parameters are modeled as positive definite lognormal random variables. This is in line with the perturbations in Girotto et al. (2014b) on the precipitation rate, but we also perturb the melt rate. Moreover, we assume that the ensemble of net accumulation rates is on average unbiased due to the applied downscaling method (Østby et al., 2017) and thus assign the two bias parameters a mean of unity. The precipitation rates are also perturbed by the same bias parameter in the computation of the heat advected by precipitation $\left(Q_{\mathrm{P}}\right)$ in the surface energy balance that contributes to the melt rate $M_{n}$.

In addition to the mass balance forcing, the peak subgrid coefficient of variation $\chi$ (Sect. 3.1.1) is a source of uncertainty. We assume a prior mean of 0.4 for $\chi$, which cor- responds to the value provided by Liston (2004) for "Arctic tundra". Moreover, $\chi$ is assumed to be double bounded between 0 and 0.8 , with negative values being unphysical and the upper bound close to the maximum value in Liston (2004). Furthermore, both the initial ground heat flux at the onset of melt $\left(Q_{0}\right)$ and the minimum snow albedo $\left(\alpha_{\min }\right)$ are uncertain, and we also assume that these are double bounded.

The probability distributions of double-bounded random variables are modeled as logit-normal distributions, with the logit transform for a variable $x$ bounded between $a$ and $b$ given by

$$
\widetilde{x}=\operatorname{logit}_{(a, b)}(x)=\ln \left(\frac{x-a}{b-a}\right)-\ln \left(1-\frac{x-a}{b-a}\right),
$$

while the inverse transform is given by

$x=\operatorname{logit}_{(a, b)}^{-1}(\widetilde{x})=a+(b-a) /\left(1+e^{-\widetilde{x}}\right)$.

To generate a prior ensemble of a logit-normally distributed random variable, we first apply the logit transform to the 
mean. Then, we add $N_{\mathrm{e}}$ realizations of Gaussian white noise with a consistent variance to the transformed mean and subsequently apply the inverse transform. We emphasize that through the perturbation parameters we effectively perturb the melt rate, precipitation rate and coefficient of variation. By performing a subsequent ensemble integration of the SSM, we also get an ensemble of state variables that are consistent with the prior perturbation parameter ensemble.

\subsubsection{Batch smoothers}

Here, we describe our implementation of three batch smoother schemes: the ES-MDA, the ES and the PBS. The ES-MDA is our focus, while the two latter schemes are used for comparison. In a batch smoother all the observations, in this case all fSCA retrievals from the snow cover depletion during one melt season, are assimilated at once in a single batch (Dunne and Entekhabi, 2005), as opposed to sequentially as in a filter (Bertino et al., 2003). We follow the conventional notation in the DA literature, as laid out in Ide et al. (1997). Let $N_{\mathrm{e}}, N_{\mathrm{o}}, N_{\mathrm{a}}, N_{\mathrm{s}}, N_{\mathrm{p}}$ and $N_{\mathrm{t}}$ denote the number of ensemble members, observations, assimilation cycles, state variables, perturbed parameters and time steps, respectively, during an annual (September-August) model integration. $\mathbf{X}$ is the $\left(N_{\mathrm{S}} \times N_{\mathrm{t}}\right) \times N_{\mathrm{e}}$ matrix containing the ensemble of states ( $\mathrm{fSCA}_{n, j}, D_{m, n, j}$ and $\mu_{n, j}$ ), and $\boldsymbol{\Theta}$ is the $N_{\mathrm{p}} \times N_{\mathrm{e}}$ matrix containing the ensemble of perturbation parameters listed in Table 4 . The $N_{\mathrm{o}} \times 1$ observation vector $\boldsymbol{y}$ contains all the fSCA satellite retrievals during the ablation season (Sect. 3.2), $\mathbf{Y}$ is the $N_{\mathrm{o}} \times N_{\mathrm{e}}$ matrix containing the ensemble of perturbed fSCA satellite retrievals and $\widehat{\mathbf{Y}}$ is the $N_{\mathrm{o}} \times N_{\mathrm{e}}$ matrix containing the ensemble of predicted fSCA observations. $\mathbf{H}$ is the linear observation operator, which is a binary $N_{\mathrm{o}} \times\left(N_{\mathrm{S}} \times N_{\mathrm{t}}\right)$ matrix that picks out the predicted fSCA observations from the ensemble of states, and $\mathbf{R}$ is the $N_{\mathrm{o}} \times N_{\mathrm{o}}$ diagonal observation error covariance matrix containing the observation error variances (Sect. 3.2).

The ES-MDA (Emerick and Reynolds, 2013) is an iterative scheme, requiring multiple ensemble model integrations and analysis steps. Collecting the perturbed and predicted observations during the ensemble integration into a batch and performing the analysis step is referred to as one assimilation cycle, and we will let the current iteration number be denoted as $\ell$. In such a case, the ES-MDA scheme is set up as follows, for $\ell \in 0: N_{\mathrm{a}}$ iterations:

1. Run an ensemble model integration; i.e., for $n \in 0$ : $\left(N_{\mathrm{t}}-1\right)$ time steps compute

$$
\mathbf{X}_{n+1}^{(\ell)}=\mathcal{M}\left(\mathbf{X}_{n}^{(\ell)}, \Theta^{(\ell)}\right)
$$

where $\mathcal{M}$ is the SSM operator defined through equations Eq. (1), Eq. (11) and Eq. (13).
2. If $\ell<N_{\mathrm{a}}$ (otherwise stop the algorithm here), collect the batch of predicted observations,

$\widehat{\mathbf{Y}}^{(\ell)}=\mathbf{H} \mathbf{X}^{(\ell)}$,

and perturbed observations,

$\mathbf{Y}^{(\ell)}=\mathbf{y} \otimes \mathbf{1}^{T}+\sqrt{\alpha^{(\ell)}} \mathbf{R}^{1 / 2} \boldsymbol{\epsilon}^{(\ell)}$,

where $\otimes$ is the outer product, 1 is an $N_{\mathrm{o}} \times 1$ vector of ones, the ${ }^{\mathrm{T}}$ superscript denotes the transpose, $\alpha^{(\ell)}$ is the observation error inflation coefficient and $\epsilon^{(\ell)}$ is a $N_{\mathrm{o}} \times$ $N_{\mathrm{e}}$ matrix containing zero mean Gaussian white noise with a variance of 1 .

3. Transform the perturbation parameters using analytical Gaussian anamorphosis functions $\psi$ (Bertino et al., 2003):

$\widetilde{\boldsymbol{\Theta}}^{(\ell)}=\psi\left(\boldsymbol{\Theta}^{(\ell)}\right)$.

$\psi$ is the natural logarithm and the logit for the biases and the remaining perturbation parameters, respectively.

4. Perform the Kalman-like analysis step in the transformed space:

$\widetilde{\boldsymbol{\Theta}}^{(\ell+1)}=\widetilde{\boldsymbol{\Theta}}^{(\ell)}+\mathcal{C}_{\widetilde{\mathbf{\Theta}} \widehat{\mathbf{Y}}}^{(\ell)}\left(\mathcal{C}_{\widehat{\mathbf{Y}} \widehat{\mathbf{Y}}}^{(\ell)}+\alpha^{(\ell)} \mathbf{R}\right)^{-1}\left(\mathbf{Y}^{(\ell)}-\widehat{\mathbf{Y}}^{(\ell)}\right)$.

The transformed perturbation parameter-predicted observation and predicted observation error covariance matrices are

$\mathcal{C}_{\widetilde{\mathbf{\Theta}} \widehat{\mathbf{Y}}}^{(\ell)}=\frac{1}{N_{\mathrm{e}}} \widetilde{\boldsymbol{\Theta}}^{(\ell)^{\prime}} \widehat{\mathbf{Y}}^{(\ell)^{\prime} \mathrm{T}}$

and

$\mathcal{C}_{\widehat{\mathbf{Y}} \widehat{\mathbf{Y}}}^{(\ell)}=\frac{1}{N_{\mathrm{e}}} \widehat{\mathbf{Y}}^{(\ell)^{\prime}} \widehat{\mathbf{Y}}^{(\ell)^{\prime} \mathrm{T}}$,

respectively, in which primes (') denote anomalies (deviations from the ensemble mean).

5. Apply the appropriate inverse transforms to recover the updated perturbation parameters:

$\boldsymbol{\Theta}^{(\ell+1)}=\psi^{-1}\left(\widetilde{\boldsymbol{\Theta}}^{(\ell+1)}\right)$.

$\psi^{-1}$ is the exponential and the inverse logit for the biases and the remaining perturbation parameters, respectively.

The observation error inflation coefficient $\alpha^{(\ell)}$ in Eq. (21) together with the iterations sets the ES-MDA apart from the traditional ES (Van Leeuwen and Evensen, 1996). For $N_{\mathrm{a}}=\alpha^{(\ell)}=1$, the ES scheme, which was used in the probabilistic SWE reconstruction of Durand et al. (2008) and 
Girotto et al. (2014b), is recovered. The idea behind the ESMDA is to perform multiple smaller analysis steps as opposed to one abrupt analysis step. In the case of a nonlinear model, this is expected to yield a better approximation of the true posterior (Emerick and Reynolds, 2013). A requirement for the ES-MDA to give a nearly unbiased estimate (cf. Stordal and Elsheikh, 2015) is that the coefficients satisfy $\sum_{\ell=0}^{N_{\mathrm{a}}-1} 1 / \alpha^{(\ell)}=1$. In our case this is accomplished by setting all the coefficients to $\alpha^{(\ell)}=N_{\mathrm{a}}$ and specifying $N_{\mathrm{a}}$ before any assimilation cycles are carried out. We emphasize that the analysis step (Eq. 21) only updates the perturbation parameters and a consistent ensemble of states is found from the subsequent ensemble model integration. The model constants listed in Table 2 remain unchanged by the analysis and the integration. As mentioned, the perturbation parameter matrix $\widetilde{\boldsymbol{\Theta}}$ in Eq. (21) is transformed through analytical Gaussian anamorphosis (Bertino et al., 2003) to ensure that the priors are Gaussian. In this case, the Kalman-like analysis step (Eq. 21) is variance minimizing for a linear model (Van Leeuwen and Evensen, 1996). The entire methodology, with the ES-MDA as the DA scheme, is depicted in Fig. 3.

Margulis et al. (2015) introduced the PBS for snow data assimilation. In this scheme, each particle (i.e., ensemble member; Van Leeuwen, 2009) is given an equal prior weight of $1 / N_{\mathrm{e}}$. Then, after an ensemble model integration, the normalized posterior importance weights $w_{j} \in[0,1]$ are diagnosed through the analysis step

$w_{j}=p\left(\boldsymbol{y} \mid \widehat{\mathbf{X}}_{j}\right) p\left(\widehat{\mathbf{X}}_{j}\right) / \sum_{j=1}^{N_{\mathrm{e}}}\left(p\left(\boldsymbol{y} \mid \widehat{\mathbf{X}}_{j}\right) p\left(\widehat{\mathbf{X}}_{j}\right)\right)$,

where $\widehat{\mathbf{X}}_{j}=\left[\mathbf{X}_{j} ; \boldsymbol{\Theta}_{j}\right]$ is the augmented state vector for the $j$-th particle and the Gaussian likelihoods are given by

$p\left(\boldsymbol{y} \mid \widehat{\mathbf{X}}_{j}\right)=c_{0} \exp \left[-0.5\left(\boldsymbol{y}-\widehat{\mathbf{Y}}_{j}\right)^{\mathrm{T}} \mathbf{R}^{-1}\left(\boldsymbol{y}-\widehat{\mathbf{Y}}_{j}\right)\right]$.

This is a direct application of Bayes' rule in which the normalizing denominator has two important consequences. Firstly, $c_{0}=1 / \sqrt{(2 \pi)^{N_{\mathrm{o}}}|\mathbf{R}|}$ cancels out, thus avoiding errors introduced through floating-point arithmetic $\left((2 \pi)^{N_{\mathrm{o}}}\right.$ is generally large). Secondly, the prior weights $p\left(\widehat{\mathbf{X}}_{j}\right)$ also cancel as they are equal for all particles. With Gaussian likelihoods, Eq. (25) becomes

$$
w_{j}=\frac{\exp \left[-0.5\left(\boldsymbol{y}-\widehat{\mathbf{Y}}_{j}\right)^{\mathrm{T}} \mathbf{R}^{-1}\left(\boldsymbol{y}-\widehat{\mathbf{Y}}_{j}\right)\right]}{\sum_{j=1}^{N_{\mathrm{e}}} \exp \left[-0.5\left(\boldsymbol{y}-\widehat{\mathbf{Y}}_{j}\right)^{\mathrm{T}} \mathbf{R}^{-1}\left(\boldsymbol{y}-\widehat{\mathbf{Y}}_{j}\right)\right]},
$$

where the posterior weights $w_{j}$ sum to unity. The posterior ensemble still spans the range of the prior ensemble, as the analysis step only changes the relative weights of the ensemble members and not their position within the state and perturbation parameter space. Marginal cumulative distributions are recovered through the individual ranking of the ensembles of state variables and perturbation parameters followed by a cumulative summation of the correspondingly sorted weights. These distributions allow for the estimation of quantile values. Note that the PBS is equivalent to running a particle filter without re-sampling and using the prior as the importance density (see Van Leeuwen, 2009). As such, the PBS corresponds to the generalized likelihood uncertainty estimation method (GLUE; Beven and Binley, 1992) with a Gaussian likelihood function. Due to the absence of re-sampling, even for medium-dimensional systems with a large number of observations to be assimilated, the PBS can become degenerate with very few particles carrying the majority of the importance weights (Van Leeuwen, 2009). Nevertheless, a major advantage of the PBS is its computational efficiency, requiring only one ensemble model integration and one efficient analysis step (Eq. 27). In this study, the PBS and the ES are used to benchmark the ES-MDA.

\section{Results}

\subsection{Interannual variability and comparison to field measurements}

In this section, we present results of the ES-MDA scheme with 100 ensemble members and four assimilation cycles (Sect. 3.3.2) for all the years and sites where snow surveys were conducted. Figure 4 shows the time series of the prior and posterior fSCA (panel a) and mean SWE (panel b) estimates, as well as the assimilated fSCA satellite retrievals (panel a) and the independently observed peak mean SWE (from the snow surveys, panel b). The assimilation generally brings the posterior estimates closer to the observed fSCA and considerably constrains the spread of the ensemble compared to the prior. For some occasions - such as Bayelva in 2008, Bayelva in 2009 and Kvadehuksletta in 2016 - the timing of the snowmelt in the prior is significantly biased by as much as 3 weeks compared to the assimilated fSCA retrievals. Even if the prior ensemble does not encompass the retrievals, the iterative ES-MDA scheme allows the posterior to converge towards the fSCA observations (panel a), leading to much improved SWE estimates (panel b). On other occasions, such as 2015 at Bayelva and 2016 at Steinflåen plateau, the prior ensemble is a reasonable estimate and the assimilation merely constrains the spread of the ensemble and adjusts the median slightly. Both for Bayelva in 2015 and Kvadehuksletta in 2016, some of the early fSCA retrievals, which indicate a slight ablation, are completely ignored by the assimilation, as this early onset of melt is inconsistent with the model - even when biases are accounted for. However, this ablation could be real and due to processes not accounted for in the model, such as wind erosion.

Field measurements of peak mean SWE are available for years with low $(2008,2016)$, medium $(2013,2015)$ and high $(2009,2014)$ values of peak mean SWE, ranging from $0.08 \mathrm{~m}$ water equivalent (w.e.) (Kvadehuksletta in 2016) to 


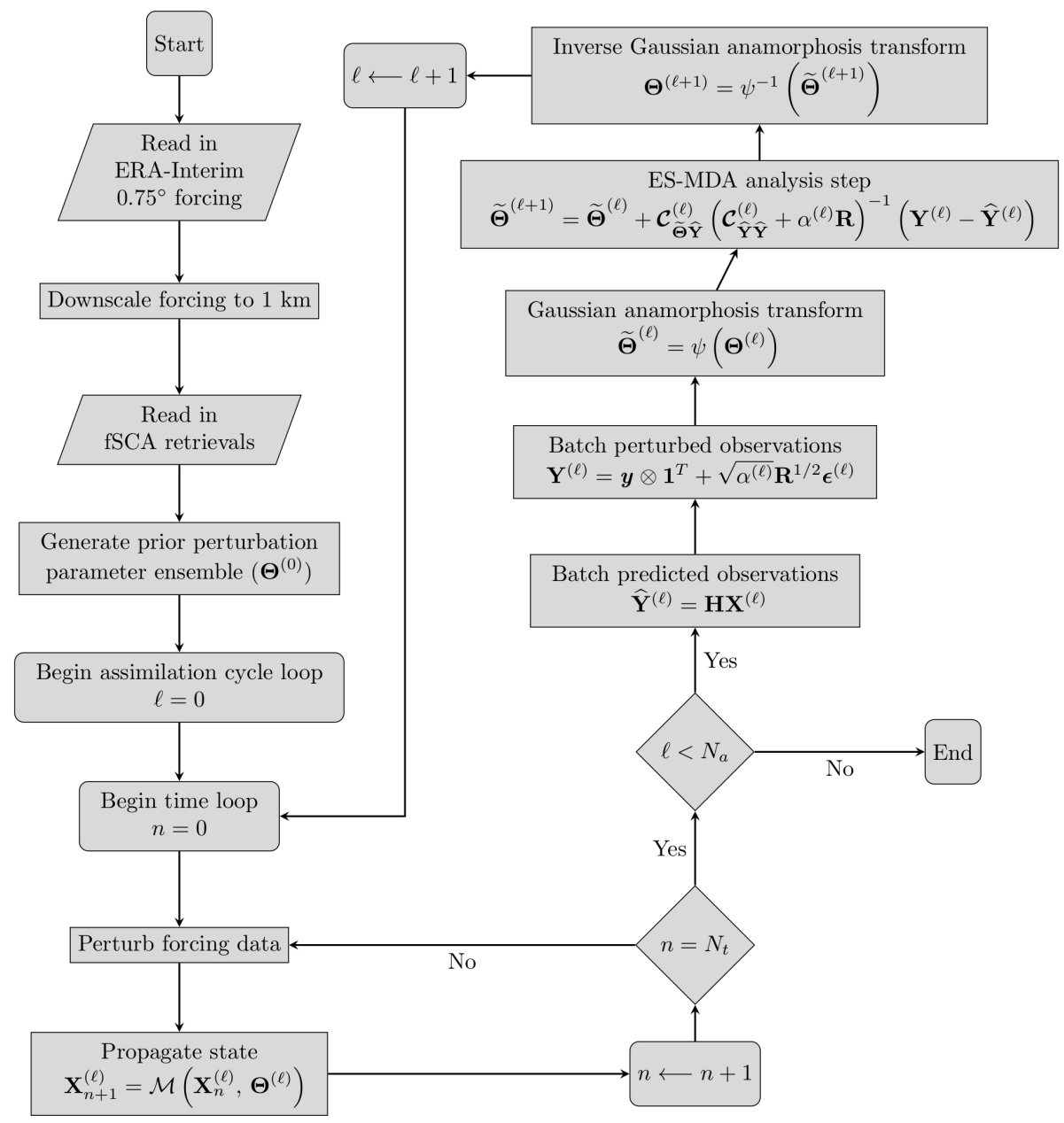

Figure 3. Flowchart depicting the methodology with the ES-MDA as the DA scheme. Symbols are defined in the text.

$0.48 \mathrm{~m}$ w.e. (Bayelva in 2014). With the exception of two cases (Bayelva in 2013 and Steinflåen plateau in 2016), the assimilation brings the ensemble median closer to the observed peak mean SWE, while at the same time constraining the spread of the ensemble. We emphasize that the assimilation performs a global bias correction for peak SWE. This is especially evident for Kvadehuksletta in 2016, for which the assimilation unrealistically truncates the duration of the snow season as a result of a strong correction for the positive bias. Both in 2008 and 2009 for Bayelva, the ES-MDA shifts the estimates to better match field measurements of SWE (which were not assimilated), despite the prior range being far from the observations. The posterior ensemble median peak mean SWE is generally close to the independently observed peak mean SWE, but absolute relative differences up to $40 \%$ (minimum: 0.5\%; mean: 19\%) occur.

Figure 5 displays the prior, posterior and observed peak SSDs for the years and sites with field measurements. Again, with the exception of Bayelva in 2013 and Steinflån plateau in 2016, the assimilation brings the mean of the peak SSD closer to the observations. The agreement between the pos- terior and observed mean value is striking for a number of years and sites, such as Bayelva in 2009 and 2014 as well as Kvadehuksletta in 2016. Furthermore, the shapes of the observed and posterior distributions agree well, for example, for Bayelva in 2008, 2013 and 2016. Once more, the correction from prior to posterior is largest for Bayelva in 2008 and 2009, for which the prior fSCA was furthest from the satellite retrievals. The prior ensemble SSD, apart from Bayelva in 2013, is generally too positively skewed (i.e., has a long tail) compared to the observed SSD. On some occasions the match between the posterior and observed SSDs is poor, such as Steinflåen plateau in 2016 and Bayelva in 2015 . We conclude that the analysis typically improves the fit between modeled and observed snow distributions. Some of the observed distributions, such as that for Kvadehuksletta in 2016, are hard to match as they do not conform well to a lognormal distribution, possibly due to the limited number of sample points (Sect. 2.2).

The posterior bias parameters can be directly evaluated by comparing the bias-corrected forcing to field measurements. Due to a lack of snowfall observations (see Boike et al., 

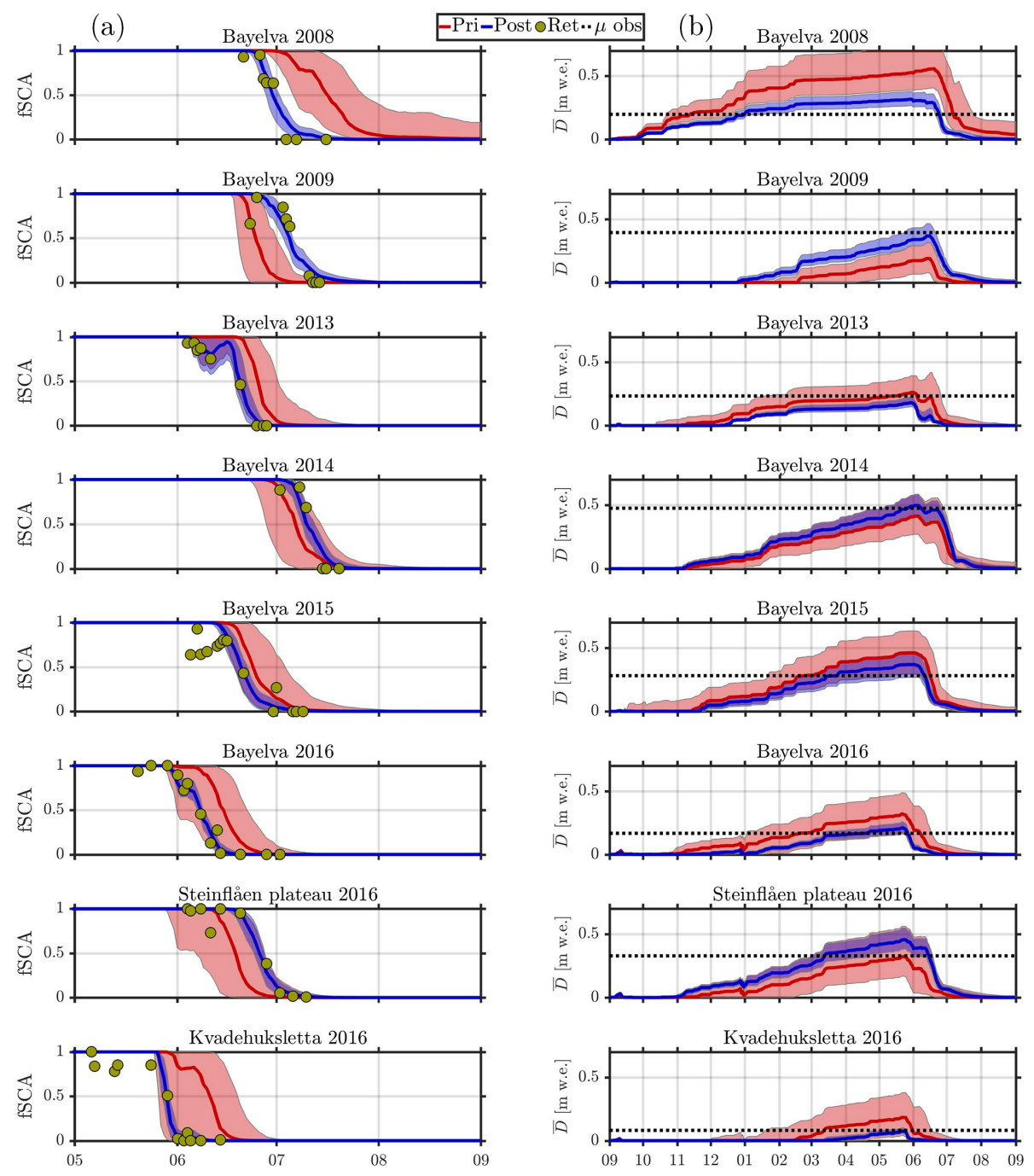

Figure 4. Time evolution of the prior (red) and ES-MDA $\left(N_{\mathrm{a}}=4, N_{\mathrm{e}}=10^{2}\right)$ posterior (blue) fSCA (column a) and mean SWE $(\bar{D} ;$ column b); shading: 90th-percentile range; solid lines: ensemble median; yellow dots: assimilated MODIS and Sentinel-2 fSCA retrievals; dotted black line: independently observed peak mean SWE $(\mu)$ from snow surveys (Sect. 2.2); $x$ axis: months. These results are from a single run.

2017), a direct evaluation of the precipitation bias parameter is not possible. However, the melt bias parameter can be evaluated by comparing the estimated snowmelt flux (which is directly proportional to the perturbed melt depth) to fieldbased values. For June 2008, Westermann et al. (2009) estimate an average snowmelt flux of $27 \mathrm{Wm}^{-2}$, which compares well to the ES-MDA posterior median (averaged for the same period) of $29 \mathrm{Wm}^{-2}$, while the prior median is too low at $19 \mathrm{Wm}^{-2}$.

In ensemble-based data assimilation the spread of the posterior ensemble should represent the uncertainty. To verify this, one can compare two metrics: the residual, i.e., the instantaneous posterior RMSE of the ensemble relative to the corresponding independent field measurement, and the ensemble standard deviation (e.g., Evensen, 2009). For this comparison we define the relative residual as the ratio of the residual to the standard deviation. Ideally this ratio should have a value of 1 , which indicates that the two metrics are equal, so that the posterior ensemble spread accurately captures the estimation uncertainty. For the fSCA, peak mean SWE and peak subgrid coefficient of variation, the average (over all available field measurements) relative residuals were $2.22,1.53$ and 1.66 , respectively, so the posterior ensemble underestimates the uncertainty. This effect has been extensively described by Evensen (2009); it arises in part because of model structural errors related to neglected physical processes (Sect. 3.1). Still, the assimilation is generally able to simultaneously (but not to the same extent) reduce the spread and the error in the ensemble (Fig. 4). 

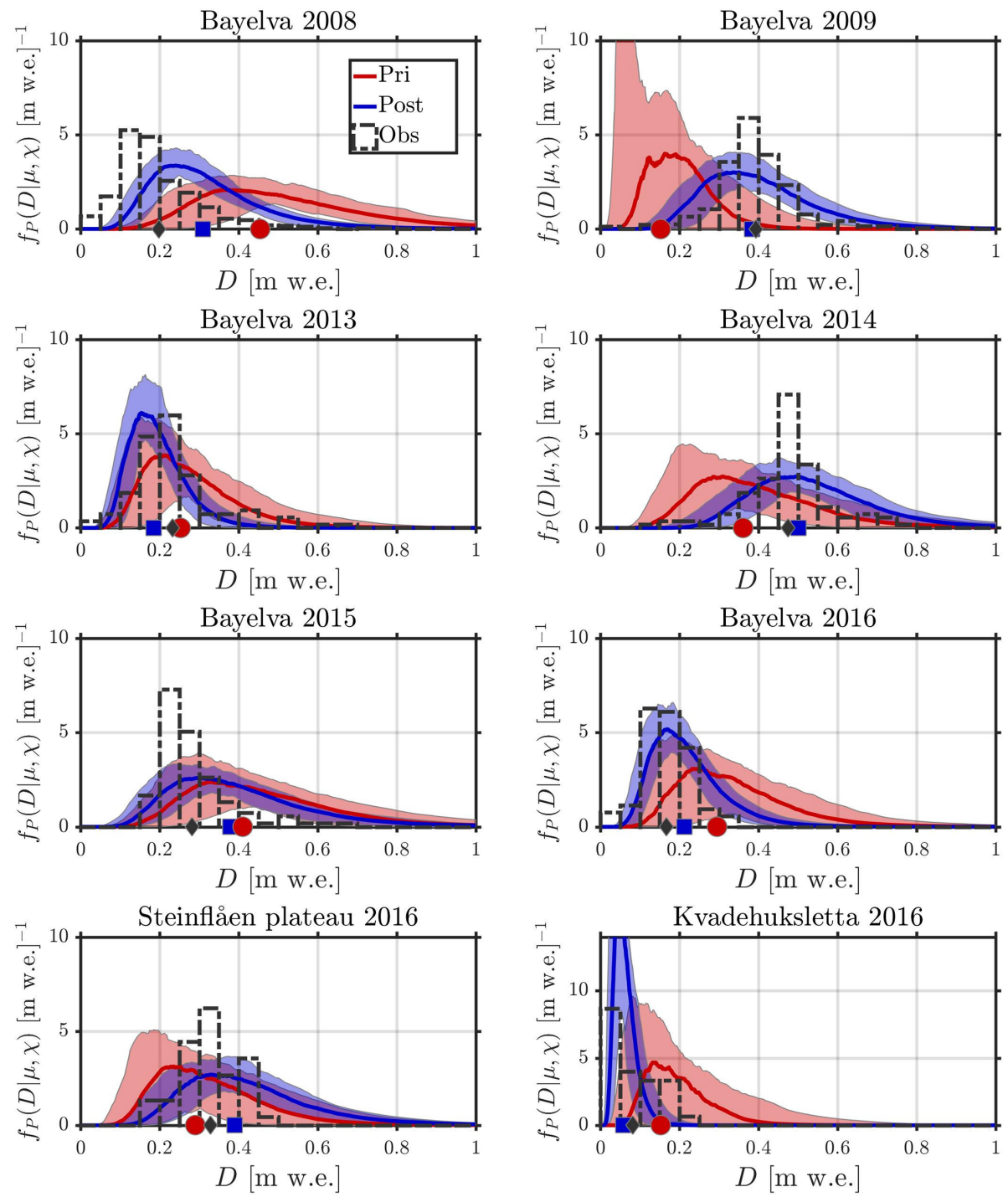

Figure 5. Prior (red), ES-MDA $\left(N_{\mathrm{a}}=4, N_{\mathrm{e}}=10^{2}\right)$ posterior (blue) and the corresponding independently observed (from snow surveys; dashed black) peak subgrid SWE distributions; shaded areas: 90th-percentile range; solid lines: ensemble median; markers: mean value. These results are from a single run.

\subsection{Evaluation of data assimilation schemes}

In addition to the ES-MDA scheme, we evaluate the PBS and ES (Sect. 3.3.2) with regards to field measurements, using an ensemble size of 100 members for all schemes. Three error metrics are summarized in Table 5: the bias (mean error), RMSE and square correlation coefficient. For the fSCA, all the schemes achieve a major improvement relative to the prior, with an almost 10 -fold reduction in bias, a halving of RMSE and an almost perfect correlation to the field measurements of fSCA (Sect. 2.2). For the peak mean SWE $(\mu)$, the PBS performs best in terms of RMSE and bias, followed closely by the ES-MDA, which, in turn, has the highest correlation coefficient. With regards to the peak subgrid coefficient of variation $(\chi)$, the ES-MDA performs best across all the metrics, tying with ES for (absolute) bias and the PBS for RMSE. As considerably more field measurements are available for fSCA than for $\mu$ and $\chi$, the evaluation for fSCA must be considered more robust. The scatterplots in Fig. 6 visualize the performance of the prior and all the considered DA schemes relative to the field measurements.

Observed, prior and posterior peak mean SWE and peak subgrid coefficient of variation for different years/sites are shown in Fig. 7. As discussed in Sect. 1, the assimilation moves the posterior peak mean SWE estimates closer to the observed peak mean SWE in most cases when compared to the prior. However, clear performance differences are found between the different schemes for a number of situations. In 2008, the PBS is not able to correct for as much of the bias in the peak mean SWE as the ES-MDA and the ES. For the 
Table 5. Summary of evaluation metrics - i.e., bias, RMSE and square correlation coefficient $\left(R^{2}\right)-$ for the fSCA, peak SWE $(\mu)$ and peak subgrid coefficient of variation $(\chi)$. These metrics are based on comparisons to all the field measurements presented in Sect. 2.2 with the number of observations for the comparisons in brackets next to the corresponding symbols. All the metrics are averaged over $10^{2}$ independent runs, each with 100 ensemble members. The ES-MDA was run with $N_{\mathrm{a}}=4$ assimilation cycles.

\begin{tabular}{|c|c|c|c|c|c|c|c|c|c|c|c|c|}
\hline \multirow[b]{2}{*}{ Symbol } & \multicolumn{3}{|c|}{ Prior } & \multicolumn{3}{|c|}{ ES-MDA } & \multicolumn{3}{|c|}{ ES } & \multicolumn{3}{|c|}{ PBS } \\
\hline & Bias & RMSE & $R^{2}$ & Bias & RMSE & $R^{2}$ & Bias & RMSE & $R^{2}$ & Bias & RMSE & $R^{2}$ \\
\hline fSCA (106) & 0.21 & 0.02 & 0.80 & 0.03 & 0.01 & 0.97 & 0.03 & 0.01 & 0.97 & 0.03 & 0.01 & 0.97 \\
\hline$\mu(8)$ [m w.e.] & 0.13 & 0.21 & 0.01 & 0.06 & 0.09 & 0.77 & 0.06 & 0.12 & 0.76 & 0.06 & 0.08 & 0.76 \\
\hline$\chi(8)$ & 0.01 & 0.16 & 0.00 & -0.02 & 0.13 & 0.37 & 0.02 & 0.14 & 0.33 & -0.03 & 0.13 & 0.06 \\
\hline
\end{tabular}
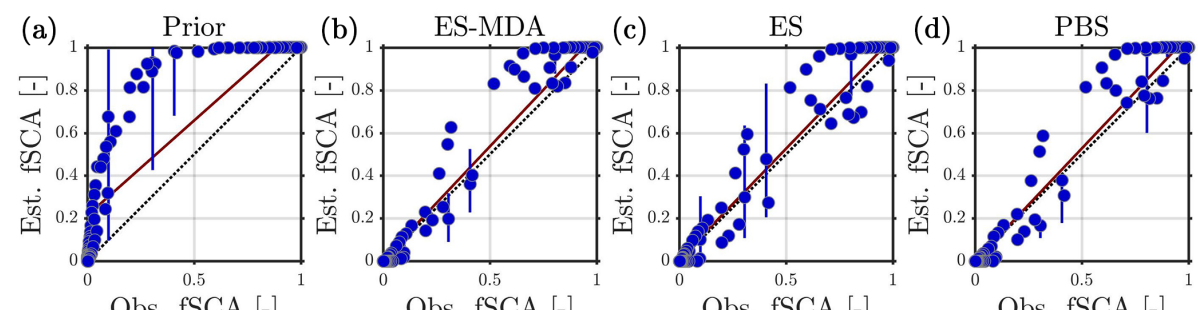

Obs. fSCA [-]

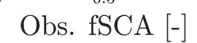

Obs. fSCA [-]
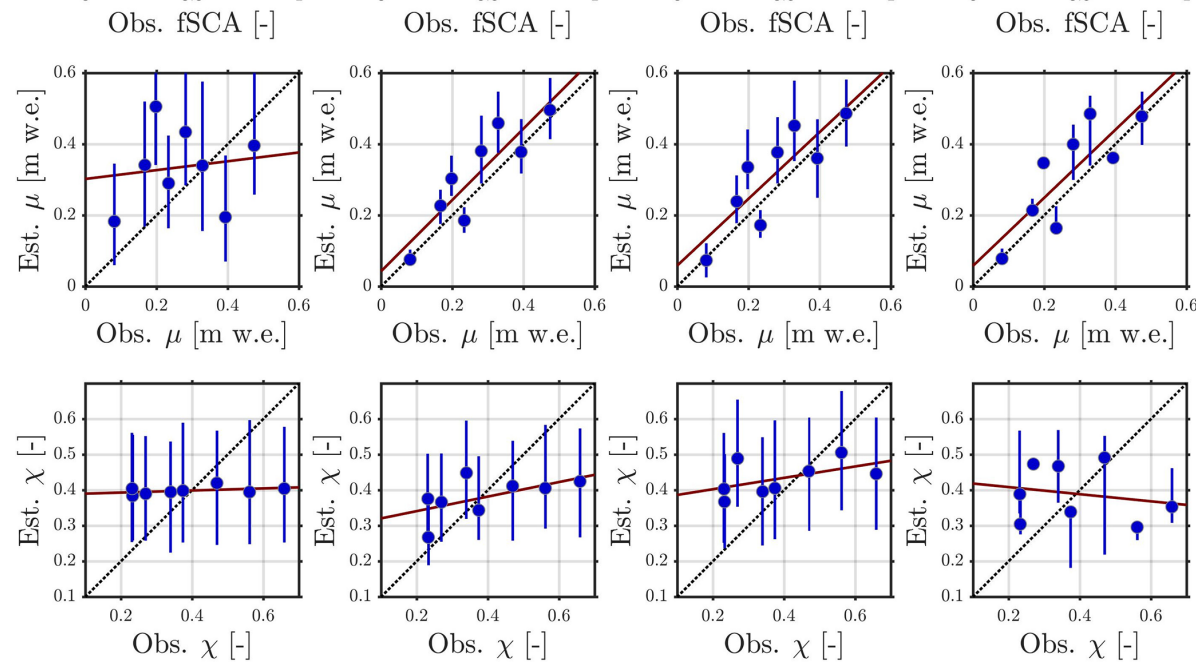

Figure 6. Scatterplots of the prior median (column a) as well as ES-MDA $\left(N_{\mathrm{a}}=4\right.$; column b), ES (column c) and PBS (column d) posterior median estimates of fSCA (top row), peak mean SWE $\mu$ (middle row) and peak subgrid coefficient of variation $\chi$ (bottom row) versus the observations (field measurements); error bars: 90th-percentile range; all DA schemes were run with $10^{2}$ ensemble members; one to one: dotted black line; linear best fit: solid red line. These results are from a single run.

remaining years, the performance of the schemes in terms of estimating peak mean SWE is similar, but the spread of the ES is by far the largest, followed by the PBS and the ESMDA. The PBS ensemble shows indications of degeneracy for some years (e.g., 2008 and 2009) where the median coincides with either the 5th- or 95th-percentile value. This indicates that the majority of the weight in the PBS is carried by just a few ensemble members. For the coefficient of variation, the 90th-percentile range of the ES-MDA posterior ensemble typically encompassed the observed value (with two exceptions), while this was not true to the same extent for the ES (three exceptions) and the PBS (five exceptions). These performance differences explain the higher correlation coeffi- cient for the coefficient of variation for the ES-MDA scheme (Table 5). The PBS also shows signs of degeneracy (e.g., Bayelva in 2009) for the coefficient-of-variation estimation. On some occasions (e.g., Bayelva in 2008, 2009 and 2014), the posterior ensemble median is effectively pulled closer to the observed coefficient of variation when compared to the prior. On the same occasions the ensemble spread is slightly constrained. Compared to the peak mean SWE, it is much harder to constrain estimates of the coefficient of variation regardless of scheme, although it is possible to shift the ensemble in the right direction.

We gauged the sensitivity of the three batch smoother schemes with respect to ensemble size and the number of as- 

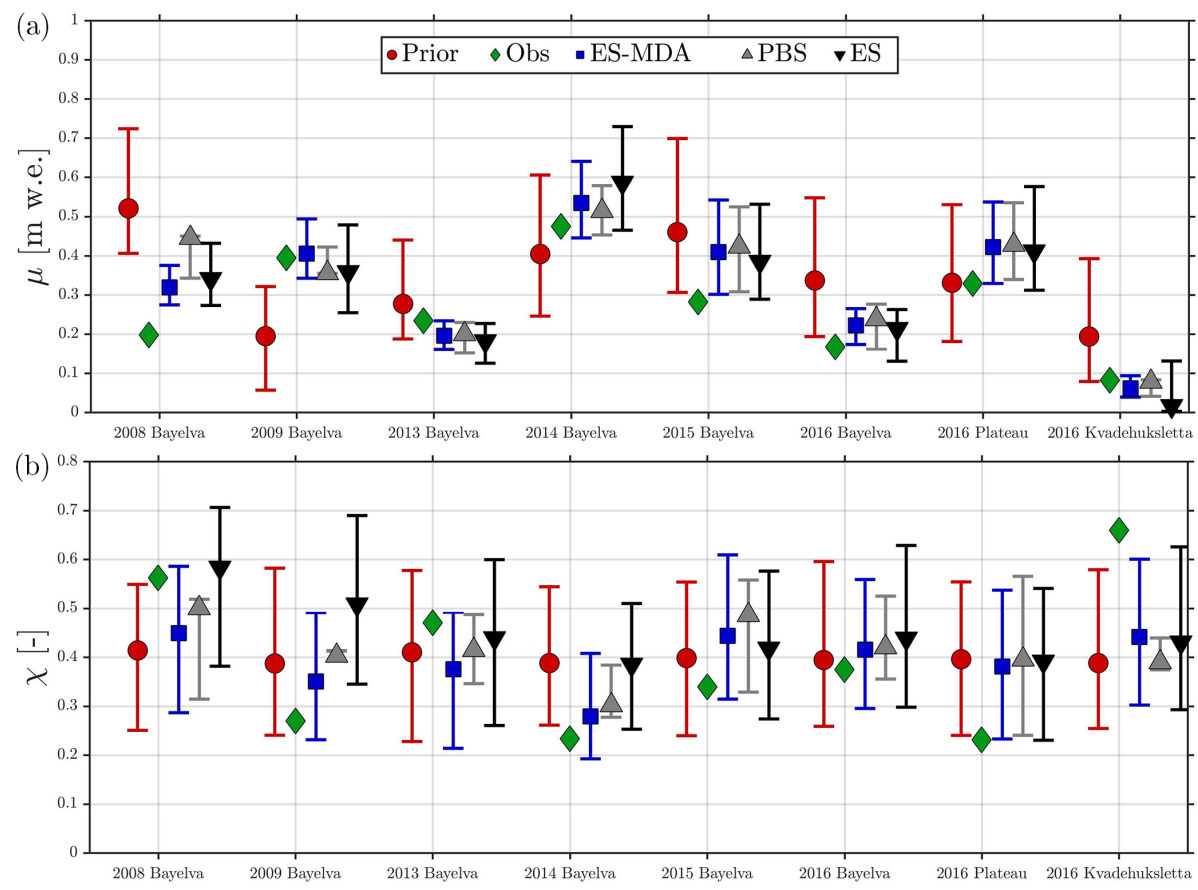

Figure 7. Prior median, observed, ES-MDA (with $N_{\mathrm{a}}=4$ ), PBS and ES posterior median peak mean SWE $\mu$ (a) and peak subgrid coefficient of variation $\chi(\mathbf{b})$; error bars: 90th-percentile range; all DA schemes were run with $10^{2}$ ensemble members. These results are from a single run.

similation cycles by considering the fractional improvement (FI) in RMSE that was achieved through the analysis step based on all available field measurements (Fig. 8). On the one hand, the PBS requires an ensemble size of 1000 to converge to a stable FI of around 75, 20 and $60 \%$ for the fSCA, peak subgrid coefficient of variation and peak mean SWE, respectively. On the other hand, the ES-MDA with four assimilation cycles converges with just 100 ensemble members at similar FIs to the PBS. The ES performs worst regardless of ensemble size, with FIs of around 70, 10 and 55\% even with $10^{5}$ ensemble members, requiring 100 ensemble members for convergent results. For all schemes the available validation data suggest that the greatest improvements are achieved for ISCA, followed by peak mean SWE, while by far the lowest improvements are found for the peak subgrid coefficient of variation. With 100 ensemble members, the ES-MDA converges to a stable performance at four assimilation cycles; i.e., there is no marked increase in FI for more cycles (Fig. 8, bottom right).

\subsection{Effects of observation error and assimilation frequency}

The effects of observation error and assimilation frequency are studied by running the ES-MDA $\left(N_{\mathrm{e}}=10^{2}, N_{\mathrm{a}}=4\right)$ and assimilating first only MODIS and then both MODIS and Sentinel-2 retrievals for the 2016 snow season at all study sites. As discussed in Sect. 3.2, the Sentinel-2 fSCA re- trievals are based on higher-resolution optical reflectance retrievals. As such they are expected to be less prone to representativeness error and thus observation error since the area in which the snow surveys were conducted is more accurately covered by the retrievals. Furthermore, the Sentinel-2 scenes used for fSCA retrievals were manually checked to be cloud free, which was not the case for the MODIS scenes. Table 6 summarizes various performance metrics for the two different runs. For the peak mean SWE depth $(\mu)$, there is no difference when including Sentinel-2 fSCA retrievals in the assimilation. For the coefficient of variation $(\chi)$, however, there is an increase in FI for both the bias and the RMSE, as well as an increase in the square correlation coefficient. Sentinel-2 fSCA retrievals with lower observation error help to further constrain the shape of the snow depletion curve which explains the improvement in the $\chi$ estimation. We emphasize that this evaluation is based on the only three available field measurements of $\mu$ and $\chi$ in 2016 (from the snow surveys), so that these preliminary results need to be consolidated by future studies with more validation data.

\section{Discussion}

\subsection{Interannual variability and comparison to field measurements}

For all considered years and sites, the ES-MDA scheme both brings the ensemble median fSCA closer to the observed 

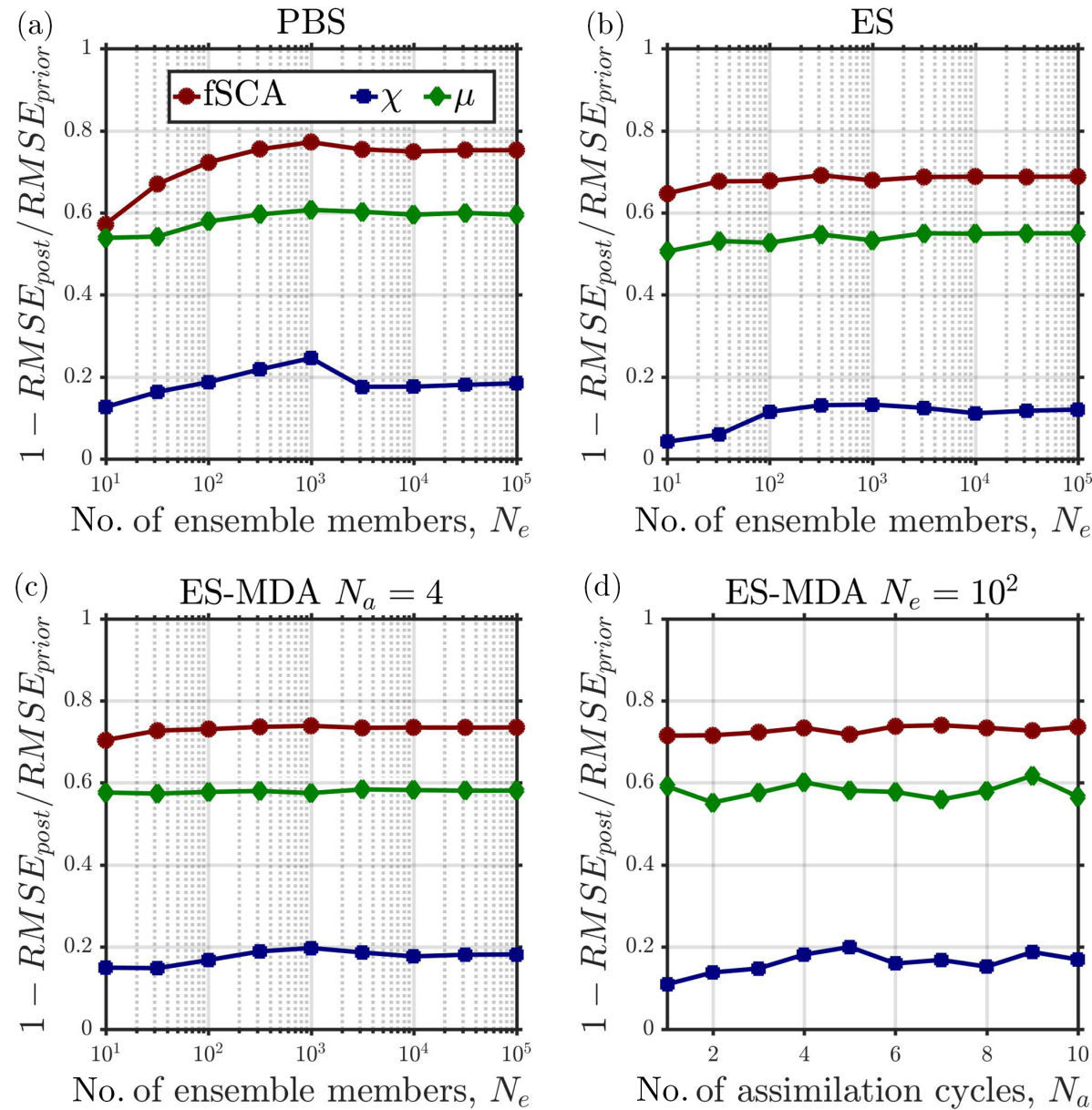

Figure 8. Fractional improvement in RMSE through the analysis step ( 1 being perfect and 0 no effect) as a function of the number of ensemble members for the fSCA, peak mean SWE $\mu$ and coefficient of variation $\chi$; (a) particle batch smoother, PBS; (b) ensemble smoother, ES; (c) ensemble smoother with multiple data assimilation, ES-MDA; (d) FI as a function of assimilation cycles in the ES-MDA. The FIs for $N_{\mathrm{e}} \leq 100$ are averaged over $10^{2}$ independent ensemble model integrations. Errors were computed based on comparisons to all the corresponding field measurements presented in Sect. 2.2.

fSCA and significantly constrains the spread of the ensemble (Fig. 4). Thus, the posterior effectively fills the gaps in the remotely sensed fSCA time series using a physically based snow model which is bias-corrected through the assimilation, while at the same time accounting for uncertainties in the retrievals. In addition, the ES-MDA is generally able to correct the prior estimates of the peak mean SWE towards the independently observed values, which is essentially achieved through a bias correction of the model forcing. Although the downscaled forcing is biased, it is a more reliable input than forcing data obtained directly from coarse-scale reanalyses (Østby et al., 2017). For example, the lapse rate correction on temperature in the downscaling (cf. Fiddes and Gruber, 2014) influences the snowfall and melt rates at the more elevated Steinflåen plateau. This effect is not captured in the reanalysis product (Dee et al., 2011), for which the elevation of the nearest grid point is near sea level.
An inherent equifinality problem (see Beven, 2006) exists in SWE reconstruction since different perturbation parameter sets can provide similar results. For example, if the prior fSCA melts out earlier than the observations, this could be due to the prior precipitation having a negative bias, the prior melt having a positive bias or a combination of these two. The opposite would be true if the prior fSCA melts out too late. It is not possible to resolve this equifinality problem with observations of fSCA alone. A key assumption in deterministic SWE reconstruction is that the melt flux is more constrained than the precipitation so that uncertainty in the melt is ignored (Slater et al., 2013). We perturb both the precipitation and the melt, although the latter is assigned a lower uncertainty (Table 4). Through the assimilation we obtain snowmelts that are consistent with the observed snow cover depletion. The close match of the posterior peak mean SWE estimates to the independent field measurements (Fig. 7) suggests that the assimilation yields consistent accumulations 
Table 6. Summary of evaluation metrics, i.e., fractional improvement in bias and RMSE, as well as prior and posterior square correlation coefficient $\left(R^{2}\right)$, using the ES-MDA $\left(N_{\mathrm{e}}=10^{2}, N_{\mathrm{a}}=4\right)$ for peak mean $\operatorname{SWE}(\mu)$ and coefficient of variation $(\chi)$ when assimilating only MODIS as well as assimilating both MODIS and Sentinel-2 observations. These metrics are based on a comparison to all the snow surveys conducted in 2016 (see Table 1) and are averaged over $10^{2}$ independent runs, each with 100 ensemble members.

\begin{tabular}{|c|c|c|c|c|c|c|c|c|c|}
\hline \multirow[b]{2}{*}{ Symbol } & \multirow[b]{2}{*}{ No. of obs } & \multicolumn{4}{|c|}{ MODIS } & \multicolumn{4}{|c|}{ MODIS+S2 } \\
\hline & & FI Bias & FI RMSE & $R_{\text {prior }}^{2}$ & $R_{\text {post }}^{2}$ & FI Bias & FI RMSE & $R_{\text {prior }}^{2}$ & $R_{\text {post }}^{2}$ \\
\hline$\mu$ & 3 & 0.61 & 0.62 & 0.67 & 1.00 & 0.61 & 0.62 & 0.69 & 1.00 \\
\hline$\chi$ & 3 & -0.77 & 0.11 & 0.00 & 0.41 & -0.60 & 0.15 & 0.00 & 0.48 \\
\hline
\end{tabular}

and that the inherent equifinality problem is of minor consequence.

Figure 5 shows that for most years the prior median is a poor estimate of the observed peak mean SWE. This indicates that a deterministic (no assimilation and unperturbed) run is not a good representation of the true state. In addition to biases in the precipitation and melt forcing, crucial processes for peak SWE, such as deposition, are not included in the simple snow model. Furthermore, the subgrid variability of the SWE is typically overestimated in the prior, with the prior distributions typically being too skewed. To circumvent these issues, a more sophisticated model (e.g., ALPINE3D; Lehning et al., 2006) accounting for wind drift could be employed, and the climatological snow distribution pattern (Sturm and Wagner, 2010) could help formulate the prior peak subgrid coefficient-of-variation distribution.

The posterior distributions are on the other hand much closer to the observed distributions for most of the years and sites considered. This suggests that there is sufficient information contained in the remotely sensed snow cover depletion to constrain the peak SSD estimates. On some occasions, especially for Bayelva in 2015, the posterior SSD is far from the observed SSD both in shape and in mean. However, the posterior estimate is still slightly better than the prior, indicating that the assimilation has a positive effect on the outcome. A similar marginal performance is found for Steinåen plateau in 2016, but the number of SWE point observations (see Table 1) is not sufficient to reliably constrain the shape of the observed distribution in this case.

\subsection{Evaluation of data assimilation schemes}

The ES-MDA exceeds or at least nearly matches the performance of the ES and the PBS, which were used in previous studies (e.g., Durand et al., 2008; Girotto et al., 2014b; Margulis et al., 2015), for all the evaluation metrics considered: bias, RMSE and correlation coefficient for fSCA, peak mean SWE and peak subgrid coefficient of variation. The performance gain over the ES is explained by the iterative nature of the ES-MDA, performing a sequence of smaller corrections in the analysis steps as opposed to one abrupt correction (Emerick and Reynolds, 2013; Stordal and Elsheikh, 2015).
Particularly in the case of a nonlinear model, as is the case for the SSM, this process of simulated annealing in the ESMDA leads to a better approximation of the posterior than a single analysis step.

At least with a low number of ensemble members the ESMDA also outperforms the PBS. A possible reason for this is that the PBS posterior ensemble spans the same range as the prior ensemble and only changes the relative weights of the ensemble members in the analysis. Thus, if the prior ensemble is so biased that it does not encompass the observations, the PBS is incapable of correcting the posterior towards the observations outside the bounds of the prior. In such a case, the region with high likelihood is very small and not necessarily close to the observations. A good example is the 2008 season at Bayelva (cf. Fig. 4 and Fig. 7), for which the prior is far away from the observed fSCA. Consequently, the PBS is unable to shift the ensemble outside the prior range as opposed to both the ES and the ES-MDA. In several years, the PBS also shows signs of degeneracy; i.e., a large part of the weight is carried by a very small number of particles. As the PBS is essentially a particle filter without re-sampling (Van Leeuwen, 2009), the weights can quickly converge on just a few particles in high-likelihood regions. Therefore, the remaining particles become redundant even for low-dimensional systems with a relatively large number of observations such as the one considered here.

The sensitivity analysis for the ensemble size is consistent with higher-dimensional models. The ES-MDA requires relatively few ensemble members for convergence, similar to the EnKF (Evensen, 2009), while the PBS requires a larger ensemble for convergence as with the PF (Van Leeuwen, 2009). The number of assimilation cycles required for convergence of the ES-MDA (four cycles) is also in line with previous studies (Emerick and Reynolds, 2013). While the PBS and the ES-MDA have not yet been compared with respect to improvement in RMSE, our findings are in agreement with previous studies for both the PBS versus the ES (Margulis et al., 2015) and the ES-MDA versus the ES (Emerick and Reynolds, 2013).

A major downside of the ES-MDA is the computational cost. The ES-MDA requires $N_{\mathrm{a}}+1$ ensemble model integrations and $N_{\mathrm{a}}$ analysis steps, where $N_{\mathrm{a}}$ (typically $\geq 2$ ) is 
the number of assimilation cycles (Sect. 3.3.2). On the other hand, the ES requires only two ensemble model integrations and a single analysis step, while the PBS only needs one ensemble model integration and a single analysis step. Based on a sensitivity analysis (Sect. 4.2), we set $N_{\mathrm{a}}=4$, so the computational cost of the ES-MDA is higher than for the other schemes. For more complex models, such as Crocus (Vionnet et al., 2012) and SNOWPACK (Bartelt and Lehning, 2002), the ES-MDA could prove to be prohibitively expensive. However, an adaptive version of the ES-MDA (Le et al., 2016) could be employed instead in which the inflation coefficients are calculated on the fly based on a cost function and the iterations stop once the algorithm converges. This scheme could significantly reduce the computational costs for applications of the ES-MDA, as it is equivalent to the ES in years for which the prior encompasses the fSCA retrievals, requiring only one iteration. In years where the prior is far from the observations to be assimilated, on the other hand, multiple data assimilation steps are performed. Furthermore, both the snow model (which has no interaction between neighboring grid cells) and the ES-MDA algorithm can be parallelized using high-performance computing.

\subsection{Effects of observation error and assimilation frequency}

All the DA methods have problems constraining the spread of the peak subgrid coefficient of variation ( $\chi$; see Fig. 7), although they can pull the median in the right direction. A likely reason is the limited information available in the remotely sensed snow cover depletion, with either too-sparse or too-uncertain fSCA retrievals. It is worth considering fSCA retrievals from even more satellites, such as Landsat and PROBA-V, which increases the chances of obtaining more cloud-free scenes. With more scenes available, it may be possible to better constrain the posterior $\chi$ ensemble: even with just a few additional retrievals from Sentinel-2 the performance was improved with respect to $\chi$ estimation across all evaluation metrics. This also points towards the benefits of including higher-resolution fSCA retrievals from the Landsat and Sentinel-2 satellites, which will be more representative and thus accurate. The effective MODIS footprint is inhomogeneous and differs markedly from the nominal $500 \mathrm{~m}$ pixel resolution when the view angle deviates from nadir (Peng et al., 2015). So, even for gridded applications, there is a considerable representativeness error in MODIS fSCA, although this is reduced when several pixels are aggregated.

\subsection{Outlook}

Several extensions to the presented ensemble-based data assimilation framework could be considered. The first is to change the grid scale of the framework from the order of $1 \mathrm{~km}$ to larger or smaller scales. For the latter, it would be possible to assimilate only Landsat- and Sentinel-2-based fSCA retrievals and operate at a grid scale on the order of $100 \mathrm{~m}$, in line with the work of, for example, Girotto et al. (2014a). For the former, one would aggregate the satellite retrievals even further and perform the assimilation at a grid scale on the order of $10 \mathrm{~km}$ or larger. This implementation could be problematic as the uniform snowmelt assumption in the SDC (Liston, 2004) may no longer be justified across such large grid cells.

Furthermore, the method could be applied to a larger domain in spatially distributed mode (i.e., multiple grid cells). In this case, fSCA assimilation could be complemented by the assimilation of GRACE TWS and/or PM SWE retrievals, which can also improve SWE estimates during the entire buildup, not only at peak SWE. Both TWS and PM retrievals could constrain the large-scale areal-average SWE estimate within the domain and thus further bias-correct the multiple grid-scale peak mean SWE estimates. However, GRACE TWS retrievals feature a very coarse resolution (around $100 \mathrm{~km}$ ) so that they would only be useful in conjunction with fSCA retrievals for very large scale applications. On the other hand, the use of higher-resolution PM SWE retrievals (order $25 \mathrm{~km}$ ) in the assimilation has shown particular promise (e.g., De Lannoy et al., 2012; Li et al., 2017). At the same time, PM SWE retrievals are not accurate in complex topography and forested areas, nor for wet and deep snowpacks (Foster et al., 2005), which might limit the applicability of such multisensor assimilation approaches.

The major problem in the assimilation of fSCA retrievals is the occurrence of clouds, which causes extended gaps in time series obtained from optical sensors. As discussed, using fSCA retrievals from even more sensors could help to fill in the gaps in the remotely sensed snow cover depletion and further constrain the peak subgrid coefficient of variation $(\chi)$. The use of additional higher-resolution $\mathrm{fSCA}$ retrievals with lower representativeness error (and thus observation error) could also prove especially beneficial for constraining $\chi$.

To reduce the computational costs of the ES-MDA, the adaptive ES-MDA (Le et al., 2016) should be considered. Furthermore, the bias-corrected ES-MDA outlined in Stordal and Elsheikh (2015) may be worth pursuing for future applications, especially when applied to bigger domains with possibly even larger misfits between the prior and the observations. Using a more complex snow model such as Crocus (Vionnet et al., 2012) or SNOWPACK (Bartelt and Lehning, 2002) may not only improve the modeled melt rates but also offer the possibility to assimilate snow grain size retrievals (cf. Painter et al., 2009), as noted by Durand et al. (2008). In addition, the method could be applied in a fully coupled land-atmosphere model. The Intermediate Complexity Atmospheric Research Model (ICAR; Gutmann et al., 2016) shows particular promise in terms of an atmospheric model that can efficiently and iteratively be run in ensemble mode, as required for applications of ES-MDA. In principle, one could run ICAR in ensemble mode coupled to a land surface 
model with an adequately complex snow scheme and assimilate fSCA (and possibly PM and TWS) retrievals with the ES-MDA to deliver a snow reanalysis.

As snow is a crucial driver for many terrestrial and atmospheric processes, the presented framework has the potential to improve process modeling in a range of disciplines, especially since the spatial resolution is considerably higher than in passive-microwave-derived SWE data sets. For example, the subgrid variability of permafrost temperatures is closely tied to that of SWE depth (e.g., Gisnås et al., 2016), which has major implications for permafrost mapping (e.g., Westermann et al., 2015b, 2017). Similarly, snow cover information is an important component of many ecological models (e.g., Kohler and Aanes, 2004), and peak SWE is intimately linked to streamflow, which is crucial for hydrology and water resource management (Andreadis and Lettenmaier, 2006; Barnett et al., 2005). Finally, knowledge of the snow distribution and snowmelt is of interest for tourism given its importance for, for example, skiing, hiking and backcountry travel.

\section{Conclusions}

In this study, we use the ensemble smoother with multiple data assimilation (ES-MDA) scheme to estimate peak SWE distributions at the kilometer scale from time series of remotely sensed fractional snow-covered area (fSCA) from MODIS and Sentinel-2. The ES-MDA is combined with analytical Gaussian anamorphosis to update perturbation parameters that are either lower or double bounded in physical space. The data assimilation is applied to a simple snow model based on the surface energy balance coupled to a probabilistic snow depletion curve. The scheme is driven by downscaled ERA-Interim reanalysis data. As such, both the model forcing and the satellite retrievals are globally available.

The results are compared to field measurements of fSCA and peak SWE distributions from Arctic sites near $\mathrm{Ny}$ Ålesund ( $79^{\circ} \mathrm{N}$, Svalbard, Norway) so that the performance can be evaluated with respect to the estimated fSCA, peak mean SWE and peak subgrid coefficient of variation. From this study, the following conclusions can be drawn:

- At the kilometer scale, the ES-MDA is able to successfully assimilate fSCA retrievals into the simple snow model and estimate the peak subgrid SWE distribution prior to the snowmelt.

- A physically based interpolation of the remotely sensed fSCA time series is obtained that takes into account uncertainties in both the model and the retrievals.

- For the peak mean SWE, the ES-MDA features an average RMSE of $0.09 \mathrm{~m}$ w.e. compared to field measurements.
- For the peak subgrid coefficient of variation that controls the width and skewness of the distribution, the ESMDA usually manages to pull the posterior median in the right direction, but the spread of the ensemble is difficult to constrain.

- By including higher-resolution fSCA retrievals from Sentinel-2, the posterior peak subgrid coefficient-ofvariation ensemble can be better constrained. This highlights the potential benefits of assimilating additional higher-resolution fSCA retrievals from sensors on board the Landsat and Sentinel-2 satellites in future work.

- In line with previous studies, the ES-MDA converges with as few as 100 ensemble members and four assimilation cycles.

- With this ES-MDA configuration, the fractional improvement in RMSE from prior to posterior is around 75, 60 and $20 \%$ for the fSCA, peak mean SWE and peak subgrid coefficient of variation.

- The ES-MDA exceeds or at least nearly matches the performance of the particle batch smoother and the ensemble smoother for all evaluation metrics considered.

As the scheme exploits high- and medium-resolution satellite images from optical sensors, it is capable of estimating snow distribution at considerably higher spatial resolutions than traditional SWE products, for example based on passive microwave retrievals. On the other hand, the scheme can only recover the peak subgrid SWE distribution prior to the onset of melt, as opposed to providing information on the seasonal evolution of the snow distribution, so that it can rather complement than replace existing SWE retrieval algorithms. However, the method could become a part of satellite-era hydrometeorological reanalysis schemes with a wide range of applications.

Code and data availability. Data and code are made available upon request from the corresponding author.

Author contributions. KA performed this study as part of his $\mathrm{PhD}$ project, co-supervised by SW and LB. KA wrote the code and performed the analysis. SW conceived the original idea and helped download the satellite data. SW performed the field measurements, with KA assisting in the final year. LB assisted with the implementation of the data assimilation. TVS performed the statistical downscaling. JB provided data from and information about the Bayelva station. The manuscript was first written by KA and then edited by all the co-authors.

Competing interests. The authors declare that they have no conflict of interest. 
Acknowledgements. This work was funded by SatPerm (239918; Research Council of Norway), in collaboration with EmblA (56801; Nordforsk) and ESA GlobPermafrost (www.globpermafrost.info). Sebastian Westermann acknowledges additional support by COUP (2449037/E10; JPI Climate; Research Council of Norway) and PermaNor (255331/E10; Research Council of Norway). Thomas Vikhamar Schuler acknowledges funding from ESCYMO (224024; Research Council of Norway). This study is a contribution to the strategic research area LATICE at the University of Oslo. We would like to thank two anonymous reviewers and Marie Dumont, all of whom contributed to significantly improving this paper.

Edited by: Marie Dumont

Reviewed by: two anonymous referees

\section{References}

Aas, K. S., Gisnås, K., Westermann, S., and Berntsen, T. K.: A Tiling Approach to Represent Subgrid Snow Variability in Coupled Land Surface-Atmosphere Models, J. Hydrometeorol., 18, 49-63, https://doi.org/10.1175/JHM-D-16-0026.1, 2017.

Andreadis, K. M. and Lettenmaier, D. P.: Assimilating remotely sensed snow observations into a macroscale hydrology model, Adv. Water Res., 29, 872-886, https://doi.org/10.1016/j.advwatres.2005.08.004, 2006.

Barnett, T. P., Adam, J. C., and Lettenmaier, D. P.: Potential Impacts of a warming climate on water availability in snow-dominated regions, Nature, 438, 303-309, https://doi.org/10.1038/nature04141, 2005.

Bartelt, P. and Lehning, M.: A physical SNOWPACK model for the Swiss avalance warning: Part I: numerical model, Cold Reg. Sci. Technol., 35, 123-145, https://doi.org/10.1016/S0165232X(02)00074-5, 2002.

Bertino, L., Evensen, G., and Wackernagel, H.: Sequential Data Assimilation Techniques in Oceanography, Int. Stat. Rev., 71, 223 241, https://doi.org/10.1111/j.1751-5823.2003.tb00194.x, 2003.

Beven, K.: A manifesto for the equifinality thesis, J. Hydrol., 320, 18-36, https://doi.org/10.1016/j.jhydrol.2005.07.007, 2006.

Beven, K. and Binley, A.: The Future of Distributed Models: Model Calibration and Uncertainty Prediction, Hydrol. Proc., 6, 279298, https://doi.org/10.1002/hyp.3360060305, 1992.

Blöschl, G.: Scaling issues in snow hydrology, Hydrological Processes, 13, 2149-2175, https://doi.org/10.1002/(SICI)10991085(199910)13:14/15<2149::AID-HYP847>3.0.CO;2-8, 1999.

Boike, J., Roth, K., and Ippisch, O.: Seasonal snow cover on frozen ground: Energy balance calculations of a permafrost site near Ny-Ålesund, Spitsbergen, J. Geophys. Res., 108, 1-11, https://doi.org/10.1029/2001JD000939, 2003.

Boike, J., Ippisch, O., Overduin, P. P., Hagedorn, B., and Roth, K.: Water, heat and solute dynamics of a mud boil, Spitsbergen, Geomorphology, 95, 61-73, https://doi.org/10.1016/j.geomorph.2006.07.033, 2008.

Boike, J., Juszak, I., Lange, S., Chadburn, S., Burke, E., Overduin, P. P., Roth, K., Ippisch, O., Bornemann, N., Stern, L., Gouttevin, I., Hauber, E., and Westermann, S.: A 20-year record (19982017) of permafrost, active layer, and meteorological conditions at a High Arctic permafrost research site (Bayelva, Spitsbergen): an opportunity to validate remote sensing data and land surface, snow, and permafrost models, Earth Syst. Sci. Data Discuss., https://doi.org/10.5194/essd-2017-100, in review, 2017.

Bruland, O., Sand, K., and Killingtveit, ̊..: Snow Distribution at a High Arctic Site at Svalbard, Hydrol. Res., 32, 1-12, 2001.

Cannone, N., Augusti, A., Malfasi, F., Pallozzi, E., Calfapietra, C., and Brugnoli, E.: The interaction of biotic and abiotic factors at multiple spatial scales affects the variability of $\mathrm{CO}_{2}$ fluxes in polar environments, Polar Biol., 39, 1581-1596, https://doi.org/10.1007/s00300-015-1883-9, 2016.

Charrois, L., Cosme, E., Dumont, M., Lafaysse, M., Morin, S., Libois, Q., and Picard, G.: On the assimilation of optical reflectances and snow depth observations into a detailed snowpack model, The Cryosphere, 10, 1021-1038, https://doi.org/10.5194/tc-10-1021-2016, 2016.

Clark, M. P., Slater, A. G., Barret, A. P., Hay, L. E., McCabe, G. J., Rajagopalan, B., and Leavesley, G. H.: Assimilation of snow covered area information into hydrologic and land-surface models, Adv. Water Res., 29, 1209-1221, https://doi.org/10.1016/j.advwatres.2005.10.001, 2006.

Clark, M. P., Hendrikx, J., Slater, A. G., Kavetski, D., Anderson, B., Cullen, N. J., Kerr, T., Hreinsson, E. O., and Woods, R. A.: Representing spatial variability of snow water equivalent in hydrologic and land-surface models: A review, Water Resour. Res., 47, 1-23, https://doi.org/10.1029/2011WR010745, 2011.

Cline, D. W., Bales, R. C., and Dozier, J.: Estimating the spatial distribution of snow in mountain basins using remote sensing and energy balance modeling, Water Resour. Res., 34, 1275-1285, https://doi.org/10.1029/97WR03755, 1998.

Cortés, G. and Margulis, S.: Impacts of El Niño and La Niña on interannual snow accumulation in the Andes: Results from a highresolution 31 year reanalysis, Geophys. Res. Lett., 44, 68596867, https://doi.org/10.1002/2017GL073826, 2017.

Cortés, G., Girotto, M., and Margulis, S. A.: Analysis of subpixel snow and ice extent over the extratropical Andes using spectral unmixing and historical Landsat imagery, Remote Sens. Environ., 141, 64-78, https://doi.org/10.1016/j.rse.2013.10.023, 2014.

Cortés, G., Girotto, M., and Margulis, S.: Snow process estimation over the extratropical Andes using a data assimilation framework integrating MERRA data and Landsat imagery, Water Resour. Res., 52, 2582-2600, https://doi.org/10.1002/2015WR018376, 2016.

De Lannoy, G. J. M., Rechile, R. H., Houser, P. R., Arsenault, K. R., Verhoest, N. E. C., and Pauwels, V. R. N.: Satellite-scale snow water equivalent assimilation into a highresolution land surface model, J. Hydrometeorol., 11, 352-369, https://doi.org/10.1175/2009JHM1192.1, 2010.

De Lannoy, G. J. M., Reichle, R. H., Arsenault, K. R., Houser, P. R., Kumar, S., Verhoest, N. E. C., and Pauwels, V. R. N.: Multiscale assimilation of Advance Microwave Scanning Radiometer-EOS snow water equivalent and Moderate Resolution Imaging Spectroradiometer snow cover fraction observations in northern Colorado, Water Resour. Res., 48, 1-17, https://doi.org/10.1029/2011WR010588, 2012.

Dee, D., Uppala, S. M., Simmons, A. J., Berrisford, P., Poli, P., Kobayashi, S., Andrae, U., Balmaseda, M. A., Balsamo, G., Bauer, P., Bechtold, P., Beljaars, A. C. M., van de Berg, L., Bidlot, J., Bormann, N., Delsol, C., Dragani, R., Fuentes, M., Geer, A. J., Haimberger, L., Healy, S. B., Hersbach, H., Hólm, E. V., 
Isaksen, L., Kållberg, P., Köhler, M., Matricardi, M., McNally, A. P., Monge-Sanz, B. M., Morcrette, J.-J., Park, B.-K., Peubey, C., de Rosnay, P., Tavolato, C., Thépaut, J.-N., and Vitart, F.: The ERA-Interim reanalysis: Configuration and performance of the data assimilation system, Q. J. Roy. Meteorol. Soc., 137, 553597, https://doi.org/10.1002/qj.828, 2011.

Dozier, J., Bair, E. H., and Davis, R. E.: Estimating the spatial distribution of snow water equivalent in the world's mountains, Wiley Interdisciplinary Reviews: Water, https://doi.org/10.1002/wat2.1140, 2016.

Drusch, M., Del Bello, U., Carlier, S., Colin, O., Fernandez, V., Gascon, F., Hoersch, B., Isola, C., Laberinti, P., Martimort, P., Meygret, A., Spoto, F., Sy, O., Marchese, F., and Bargellini, P.: Sentinel-2:ESA's Optical High-Resolution Mission for GMES Operational Services, Remote Sens. Environ., 120, 25-36, https://doi.org/10.1016/j.rse.2011.11.026, 2012.

Dunne, S. and Entekhabi, D.: An ensemble-based reanalysis approach to land data assimilation, Water Resour. Res., 41, W02013, https://doi.org/10.1029/2004WR003449, 2005.

Durand, M., Molotoch, N. P., and Margulis, S. A.: A Bayesian approach to snow water equivalent reconstruction, J. Geophys. Res., 113, D20117, https://doi.org/10.1029/2008JD009894, 2008.

Dutra, E., Balsamo, B., Viterbo, P., Miranda, P., Beljaars, A., Schär, C., and Elder, K.: An Improved Snow Scheme for the ECMWF Land Surface Model: Description and Offline Validation, J. Hydrometeorol., 11, 899-916, https://doi.org/10.1175/2010JHM1249.1, 2010.

Emerick, A. A. and Reynolds, A. C.: Ensemble smoother with multiple data assimilation, Comput. Geosci., 55, 3-15, https://doi.org/10.1016/j.cageo.2012.03.011, 2013.

Esau, I., Argentini, S., Przybylak, R., Repina, I., and Sjöblom, A.: Svalbard Meteorology, Adv. Meteorol., 2012, 1-4, https://doi.org/10.1155/2012/818473, 2012.

Evensen, G.: Data Assimilation: The Ensemble Kalman Filter, Springer-Verlag Berlin Heidelberg, https://doi.org/10.1007/9783-642-03711-5, 2009.

Fiddes, J. and Gruber, S.: TopoSCALE v.1.0: downscaling gridded climate data in complex terrain, Geosci. Model Dev., 7, 387-405, https://doi.org/10.5194/gmd-7-387-2014, 2014.

Førland, J. E., Benestad, R., Hanssen-Bauer, I., Haugen, J. E., and Skaugen, T. E.: Temperature and Precipitation Development at Svalbard 1900-2100, Adv. Meteorol., 2011, 1-14, https://doi.org/10.1155/2011/893790, 2011.

Foster, J. L., Sun, C., Walker, J. P., Kelly, R., Chang, A., Dong, J., and Powell, H.: Quantifying the uncertainty in passive microwave snow water equivalent observations, Remote Sens. Environ., 94, 187-203, https://doi.org/10.1016/j.rse.2004.09.012, 2005.

Girotto, M., Cortés, G., Margulis, S. A., and Durand, M.: Examining spatial and temporal variability in snow water equivalent using a 27 year reanalysis: Kern River watershed, Sierra Nevada, Water Resour. Res., 50, 6713-6734, https://doi.org/10.1002/2014WR015346, 2014a.

Girotto, M., Margulis, S. A., and Durand, M.: Probabilistic SWE reanalysis as a generalization of deterministic SWE reconstruction techniques, Hydrol. Proc., 28, 3875-3895, https://doi.org/10.1002/hyp.9887, 2014b.
Gisnås, K., Westermann, S., Schuler, T. V., Litherland, T., Isaksen, K., Boike, J., and Etzelmüller, B.: A statistical approach to represent small-scale variability of permafrost temperatures due to snow cover, The Cryosphere, 8, 2063-2074, https://doi.org/10.5194/tc-8-2063-2014, 2014.

Gisnås, K., Westermann, S., Schuler, T. V., Melvold, K., and Etzelmüller, B.: Small-scale variation of snow in a regional permafrost model, The Cryosphere, 10, 1201-1215, https://doi.org/10.5194/tc-10-1201-2016, 2016.

Gutmann, E., Barstad, I., Clark, M., Arnold, J., and Rasmussen, R.: The Intermediate Complexity Atmospheric Research Model (ICAR), J. Hydrometeorol., 17, 957-973, https://doi.org/10.1175/JHM-D-15-0155.1, 2016.

Hall, D. K. and Riggs, G. A.: MODIS/Terra Snow Cover Daily L3 Global 500m Grid, Version 6, Tile h18v01, https://doi.org/10.5067/MODIS/MOD10A1.006 (last access: 5 May 2017), Boulder, Colorado USA, NASA National Snow and Ice Data Center Distributed Active Archive Center, 2016a.

Hall, D. K. and Riggs, G. A.: MODIS/Aqua Snow Cover Daily L3 Global 500m Grid, Version 6, Tile h18v01, https://doi.org/10.5067/MODIS/MYD10A1.006 (last access: 5 May 2017), Boulder, Colorado USA. NASA National Snow and Ice Data Center Distributed Active Archive Center, 2016b.

Hall, D. K., Riggs, G. A., Salomonson, V. V., DiGirolamo, N. E., and Bayr, K. J.: MODIS snow-cover products, Remote Sens. Environ., 83, 181-194, https://doi.org/10.1016/S00344257(02)00095-0, 2002.

Ide, K., Courtier, P., Ghil, M., and Lorenc, A.: Unified Notation for Data Assimilation: Operational, Sequential and Variational, J. Meteorol. Soc. Japan, 75, 181-189, 1997.

Kępski, D., Luks, B., Migała, K., Wawrzyniak, T., Westermann, S., and Wojtun, B.: Terrestrial Remote Sensing of Snowmelt in a Diverse High-Arctic Tundra Environment Using Time-Lapse Imagery, Remote Sens., 9, 1-22, https://doi.org/10.3390/rs9070733, 2017.

Kohler, J. and Aanes, R.: Effect of Winter Snow and GroundIcing on a Svalbard Reindeer Population: Results of a Simple Snowpack Model, Arctic, Antarctic and Alpine Research, 36, 333-341, https://doi.org/10.1657/15230430(2004)036[0333:EOWSAG]2.0.CO;2, 2004.

Kolberg, S. A. and Gottschalk, L.: Updating of snow depletion curve with remote sensing data, Hydrol. Proc., 20, 2363-2380, https://doi.org/10.1002/hyp.6060, 2006.

Le, D. H., Emerick, A. A., and Reynolds, A. C.: An Adaptive Ensemble Smoother With Multiple Data Assimilation for Assisted History Matching, Society of Petroleum Engineers Journal, 21, 2195-2207, https://doi.org/10.2118/173214-PA, 2016.

Lehning, M., Völksch, I., Gustafsson, D., Nguyen, T. A., Stähli, M., and Zappa, M.: ALPINE3D: a detailed model of mountain surface processes and its application to snow hydrology, Hydrol. Proc., 20, 2111-2128, https://doi.org/10.1002/hyp.6204, 2006.

Li, D., Durand, M., and Margulis, S. A.: Estimating snow water equivalent in a Sierra Nevada watershed via spaceborne radiance data assimilation, Water Resour. Res., 53, 647-671, https://doi.org/10.1002/2016WR018878, 2017.

Liston, G. E.: Interrelationships among Snow Distribution, Snowmelt, and Snow Cover Depletion: Implications for Atmospheric, Hydrologic, and Ecologic Modeling, J. Appl. Meteorol., 38, 1474-1487, 1999. 
Liston, G. E.: Representing Subgrid Snow Cover Heterogeneities in Regional and Global Models, J. Climate, 17, 1381-1397, https://doi.org/10.1175/15200442(2004)017<1381:RSSCHI>2.0.CO;2, 2004.

López-Moreno, J. I., Boike, J., Sanchez-Lorenzo, A., and Pomeroy, J. W.: Impact of climate warming on snow processes in Ny-Ålesund, a polar maritime site at Svalbard, Global Planet. Change, 146, 10-21, https://doi.org/10.1016/j.gloplacha.2016.09.006, 2016.

Luce, C. H. and Tarboton, D. G.: The application of depletion curves for parameterization of subgrid variability of snow, Hydrol. Proc., 18, 1409-1422, https://doi.org/10.1002/hyp.1420, 2004.

Lüers, J., Westermann, S., Piel, K., and Boike, J.: Annual $\mathrm{CO}_{2}$ budget and seasonal $\mathrm{CO}_{2}$ exchange signals at a high Arctic permafrost site on Spitsbergen, Svalbard archipelago, Biogeosciences, 11, 6307-6322, https://doi.org/10.5194/bg-11-63072014, 2014.

Magnusson, J., Winstral, A., Stordal, A. S., Essery, R., and Jonas, T.: Improving physically based snow simulations by assimilating snow depths using the particle filter, Water Resour. Res., 53, 119, https://doi.org/10.1002/2016WR019092, 2017.

Margulis, S. A., Girotto, M., Cortés, G., and Durand, M.: A Particle Batch Smoother Approach to Snow Water Equivalent Estimation, J. Hydrometeorol., 16, 1752-1772, https://doi.org/10.1175/JHM-D-14-0177.1, 2015.

Margulis, S. A., Cortés, G., Girotto, M., and Durand, M.: A Landsat-Era Sierra Nevada Snow Reanalysis (1985-2015), J. Hydrometeorol., 17, 1203-1221, https://doi.org/10.1175/JHMD-15-0177.1, 2016.

Martinec, J. and Rango, A.: Areal Distribution of Snow Water Equivalent Evaluated by Snow Cover Monitoring, Water Resour. Res., 17, 1480-1488, https://doi.org/10.1029/WR017i005p01480, 1981.

Molotch, N. P. and Margulis, S. A.: Estimating the distribution of snow water equivalent using remotely sensed snow cover data and a spatially distributed snowmelt model: A multi-resolution, multi-sensor comparison, Adv. Water Res., 31, 1503-1514, https://doi.org/10.1016/j.advwatres.2008.07.017, 2008.

Niu, G. Y., Seo, K. W., Yang, Z. L., Wilson, C., Su, H., Chen, J., and Rodell, M.: Retrieving snow mass from GRACE terrestrial water storage change with a land surface model, Geophys. Res. Lett., 34, 1-5, https://doi.org/10.1029/2007GL030413, 2007.

Nowak, A. and Hodson, A.: Hydrological response of a HighArctic catchment to changing climate over the past 35 years: a case study of Bayelva watershed, Svalbard, Polar Res., 32, 1-17, https://doi.org/10.3402/polar.v32i0.19691, 2013.

NPI: Norwegian Polar Intsitute DEM: Terrengmodell Svalbard (S0 Terrengmodell), Delmodell 5m 2010_13828_33, available at: https://doi.org/10.21334/npolar.2014.dce53a47 (last access: 3 December 2016), 2014.

Østby, T. I., Schuler, T. V., Hagen, J. O., Hock, R., Kohler, J., and Reijmer, C. H.: Diagnosing the decline in climatic mass balance of glaciers in Svalbard over 1957-2014, The Cryosphere, 11, 191-215, https://doi.org/10.5194/tc-11-191-2017, 2017.

Painter, T. H., Rittger, K., McKenzie, C., Slaughter, P., Davis, R. E., and Dozier, J.: Retrieval of subpixel snow covered area, grain size and, and albedo from MODIS, Remote Sens. Environ., 113, 868-879, https://doi.org/10.1016/j.rse.2009.01.001, 2009.
Pedersen, C. and Winther, J.: Intercomparison and validation of snow albedo parameterization schemes in climate models, Clim. Dynam., 25, 351-362, https://doi.org/10.1007/s00382005-0037-0, 2005.

Peng, J., Liu, Q., Wang, L., Liu, Q., Fan, W., Lu, M., and Wen, J.: Characterizing the Pixel Footprint of Satellite Albedo Products Derived from MODIS Reflectance in the Heihe River Basin, China, Remote Sens., 7, 6886-6907, https://doi.org/10.3390/rs70606886, 2015.

Raleigh, M. S., Lundquist, J. D., and Clark, M. P.: Exploring the impact of forcing error characteristics on physically based snow simulations within a global sensitivity analysis framework, Hydrol. Earth Syst. Sci., 19, 3153-3179, https://doi.org/10.5194/hess-19-3153-2015, 2015.

Roth, K. and Boike, J.: Quantifying the thermal dynamics of a permafrost site near Ny-Ålesund, Svalbard, Water Resour. Res., 37, 2901-2914, https://doi.org/10.1029/2000WR000163, 2001.

Salomonson, V. V. and Appel, I.: Estimating fractional snow cover from MODIS using the normalized difference snow index, Remote Sens. Environ., 89, 351-360, https://doi.org/10.1016/j.rse.2003.10.016, 2004.

Slater, A. G. and Clark, M. P.: Snow Data Assimilation via an Ensemble Kalman Filter, J. Hydrometeorol., 7, 478-493, 2006.

Slater, A. G., Barrett, A. P., Clark, M. P., Lundquist, J. D., and Raleigh, M. S.: Uncertainty in seasonal snow reconstruction: Relative impacts of model forcing and image availability, Adv. Water Res., 55, 165-177, https://doi.org/10.1016/j.advwatres.2012.07.006, 2013.

Smith, R. B. and Barstad, I.: A Linear Theory of Orographic Precipitation, Journal of the Atmospheric Sciences, 61, 1377-1391, https://doi.org/10.1175/15200469(2004)061<1377:ALTOOP>2.0.CO;2, 2004.

Stordal, A. S. and Elsheikh, A. H.: Iterative ensemble smoothers in the annealed importance sampling framework, Adv. Water Res., 86, 231-239, https://doi.org/10.1016/j.advwatres.2015.09.030, 2015.

Sturm, M. and Wagner, A. M.: Using repeated patterns in snow distribution modeling: An Arctic Example, Water Resour. Res., 46, 1-15, https://doi.org/10.1029/2010WR009434, 2010.

Su, H., Yang, Z. L., Dickinson, R. E., Wilson, C. R., and Niu, G. Y.: Multisensor snow data assimilation at the continental scale: The value of Gravity Recovery and Climate Experiment terrestrial water storage information, J. Geophys. Res., 115, 114, https://doi.org/10.1029/2009JD013035, 2010.

Tarboton, D. G. and Luce, C. H.: Utah Energy Balance Snow Accumulation and Melt Model, Computer model techincal description and users guide, Utah Water Research Laboratory and USDA Forest Service Intermountain Research Station, Logan, Utah, 1996.

Van Leeuwen, P. J.: Particle Filtering in Geophysical Systems, Mon. Weather Rev., 137, 4089-4114, https://doi.org/10.1175/2009MWR2835.1, 2009.

Van Leeuwen, P. J. and Evensen, G.: Data assimilation and inverse methods in terms of a probabilistic formulation, Mon. Weather Rev., 124, 2898-2913, https://doi.org/10.1175/15200493(1996)124<2898:DAAIMI>2.0.CO;2, 1996.

Vionnet, V., Brun, E., Morin, S., Boone, A., Faroux, S., Le Moigne, P., Martin, E., and Willemet, J.-M.: The detailed snowpack scheme Crocus and its implementation in SURFEX v7.2, 
Geosci. Model Dev., 5, 773-791, https://doi.org/10.5194/gmd-5773-2012, 2012.

Westermann, S., Lüers, J., Langer, M., Piel, K., and Boike, J.: The annual surface energy budget of a high-arctic permafrost site on Svalbard, Norway, The Cryosphere, 3, 245-263, https://doi.org/10.5194/tc-3-245-2009, 2009.

Westermann, S., Boike, J., Langer, M., Schuler, T. V., and Etzelmüller, B.: Modeling the impact of wintertime rain events on the thermal regime of permafrost, The Cryosphere, 5, 945-959, https://doi.org/10.5194/tc-5-945-2011, 2011a.

Westermann, S., Langer, M., and Boike, J.: Spatial and temporal variations of summer surface temperatures of high-arctic tundra on Svalbard - Implications for MODIS LST based permafrost monitoring, Remote Sens. Environ., 115, 908-922, https://doi.org/10.1016/j.rse.2010.11.018, 2011 b.

Westermann, S., Langer, M., and Boike, J.: Systematic bias of winter-time land surface temperatures inferred from MODIS at a site on Svalbard, Norway, Remote Sens. Environ., 118, 162167, https://doi.org/10.1016/j.rse.2011.10.025, 2012.

Westermann, S., Boike, J., Guglielmin, M., Gisnås, K., and Etzmüller, B.: Snow melt monitoring near Ny-Ålesund, Svalbard, using Automatic Camera Systems, available at: https://doi.org/10.1594/PANGAEA.846617 (last access: 5 May 2017), Department of Geosciences, University of Oslo, 2015a.
Westermann, S., Østby, T. I., Gisnås, K., Schuler, T. V., and Etzelmüller, B.: A ground temperature map of the North Atlantic permafrost region based on remote sensing and reanalysis data, The Cryosphere, 9, 1303-1319, https://doi.org/10.5194/tc9-1303-2015, 2015 b.

Westermann, S., Langer, M., Boike, J., Heikenfeld, M., Peter, M., Etzelmüller, B., and Krinner, G.: Simulating the thermal regime and thaw processes of ice-rich permafrost ground with the landsurface model CryoGrid 3, Geosci. Model Dev., 9, 523-546, https://doi.org/10.5194/gmd-9-523-2016, 2016.

Westermann, S., Peter, M., Langer, M., Schwamborn, G., Schirrmeister, L., Etzelmüller, B., and Boike, J.: Transient modeling of the ground thermal conditions using satellite data in the Lena River delta, Siberia, The Cryosphere, 11, 1441-1463, https://doi.org/10.5194/tc-11-1441-2017, 2017.

Winther, J. G., Godtliebsen, F., Gerland, S., and Isachsen, P. E.: Surface albedo in Ny-Ålesund, Svalbard: variability and trends during 1981-1997, Global Planet. Change, 32, 127-139, https://doi.org/10.1016/S0921-8181(01)00103-5, 2002.

You, J., Tarboton, D. G., and Luce, C. H.: Modeling the snow surface temperature with a one-layer energy balance snowmelt model, Hydrol. Earth Syst. Sci., 18, 5061-5076, https://doi.org/10.5194/hess-18-5061-2014, 2014. 